\title{
Hormonal Contraception Is Associated with a Reduced Risk of Bacterial Vaginosis: A Systematic Review and Meta-Analysis
}

\author{
Lenka A. Vodstrcil ${ }^{1,2,3}$, Jane S. Hocking ${ }^{4}$, Matthew Law ${ }^{5}$, Sandra Walker ${ }^{1,2}$, Sepehr N. Tabrizi ${ }^{3,6,7}$, \\ Christopher K. Fairley ${ }^{1,2}$, Catriona S. Bradshaw ${ }^{1,2,8 *}$
}

1 Sexual Health Unit, Melbourne School of Population and Global Health, University of Melbourne, Parkville, Australia, 2 Melbourne Sexual Health Centre, Alfred Hospital, Carlton, Australia, 3 Murdoch Children's Research Institute, Parkville, Australia, $\mathbf{4}$ Centre for Women's Health, Gender and Society, Melbourne School of Population and Global Health, University of Melbourne, Parkville, Australia, 5 Kirby Institute, University of New South Wales, Coogee, Australia, 6 Department of Microbiology and Infectious Diseases, The Royal Women's Hospital, Parkville, Victoria, Australia, 7 Department of Obstetrics and Gynaecology, University of Melbourne, The Royal Women's Hospital Parkville, Victoria, Australia, 8 Department of Epidemiology and Preventative Medicine, Monash University, Melbourne, Australia

\begin{abstract}
Objective: To examine the association between hormonal contraception (HC) and bacterial vaginosis (BV) by systematic review and meta-analysis.

Methods: Medline, Web of Science and Embase databases were searched to 24/1/13 and duplicate references removed. Inclusion criteria 1) >20 BV cases; 2) accepted BV diagnostic method; 3) measure of HC-use either as combined oestrogenprogesterone $\mathrm{HC}$ (combined), progesterone-only contraception (POC) or unspecified HC (u-HC); 4 ) $\geq 10 \%$ of women using HC; 5) analysis of the association between BV and HC-use presented; 6) appropriate control group. Data extracted included: type of HC, BV diagnostic method and outcome (prevalent, incident, recurrent), and geographical and clinic-setting. Metaanalyses were conducted to calculate pooled effect sizes (ES), stratified by HC-type and BV outcome. This systematic review is registered with PROSPERO (CRD42013003699).

Results: Of 1713 unique references identified, 502 full-text articles were assessed for eligibility and 55 studies met inclusion criteria. Hormonal contraceptive use was associated with a significant reduction in the odds of prevalent BV (pooled effect size by random-effects $[\mathrm{reES}]=0.68,95 \% \mathrm{Cl} 0.63-0.73$ ), and in the relative risk (RR) of incident (reES $=0.82,95 \% \mathrm{Cl}: 0.72-0.92$ ), and recurrent (reES $=0.69,95 \% \mathrm{Cl}: 0.59-0.91) \mathrm{BV}$. When stratified by $\mathrm{HC}$-type, combined-HC and POC were both associated with decreased prevalence of BV and risk of incident BV. In the pooled analysis of the effect of HC-use on the composite outcome of prevalent/incident/recurrent BV, HC-use was associated with a reduced risk of any BV (reES $=0.78,95 \% \mathrm{Cl}: 0.74-$ 0.82).

Conclusion: HC-use was associated with a significantly reduced risk of BV. This negative association was robust and present regardless of HC-type and evident across all three BV outcome measures. When stratified by HC-type, combined-HC and POC were both individually associated with a reduction in the prevalence and incidence of BV. This meta-analysis provides compelling evidence that HC-use influences a woman's risk of BV, with important implications for clinicians and researchers in the field.
\end{abstract}

Citation: Vodstrcil LA, Hocking JS, Law M, Walker S, Tabrizi SN, et al. (2013) Hormonal Contraception Is Associated with a Reduced Risk of Bacterial Vaginosis: A Systematic Review and Meta-Analysis. PLoS ONE 8(9): e73055. doi:10.1371/journal.pone.0073055

Editor: D William Cameron, University of Ottawa, Canada

Received April 8, 2013; Accepted July 16, 2013; Published September 4, 2013

Copyright: (c) 2013 Vodstrcil et al. This is an open-access article distributed under the terms of the Creative Commons Attribution License, which permits unrestricted use, distribution, and reproduction in any medium, provided the original author and source are credited.

Funding: Two grants contributed funding to this study; an NHMRC Project Grant (1020457) \& an NHMRC Program grant (568971). The funders had no role in study design, data collection and analysis, decision to publish, or preparation of the manuscript.

Competing Interests: The authors have declared that no competing interests exist.

* E-mail: cbradshaw@mshc.org.au

\section{Introduction}

Bacterial Vaginosis (BV) is the most common cause of vaginal discharge in reproductive age women, of unknown, but probable polymicrobial aetiology. BV is associated with significant clinical sequelae including increased risk of HIV acquisition [1,2], preterm delivery [3,4] and pelvic inflammatory disease (PID) [5]. While there have been limited population-based studies, the National Health and Nutrition Survey in the United States reported a BV prevalence in 17-49 year old women of $29 \%$ [6], and an
Australian study in 17-25 year old women attending general and reproductive health services found a BV prevalence of $12 \%$ [7]. Treatment with current first line antibiotics have similar shortterm efficacy with $70-80 \%$ cure rates at one month $[8,9]$, however $\mathrm{BV}$ recurrence is common, with rates as high as $58 \%$ within 12 months [10]. No sustained improvement in cure has been derived from combining first line antibiotic therapies, using suppressive antibiotic regimens or with adjunctive probiotic approaches [11].

Interestingly, a number of observational studies have reported that women using hormonal contraceptives have a reduced risk of 
prevalent [12-15] and recurrent [10,16,17] BV. These data particularly reflect the use of combined oestrogen-progesterone contraceptive agents or "unspecified hormonal contraceptives", but several studies report a reduced risk of incident and recurrent $\mathrm{BV}$ in progesterone-only contraceptive users $[16,18]$. With over $50 \%$ of women experiencing BV recurrence following first-line antibiotic therapies, and no significant improvement in the management of $\mathrm{BV}$ in the last 20 years, identifying potential modifiable practices that influence susceptibility to BV and recurrence are integral to progressing prevention and management approaches for this important and common genital tract condition. This systematic review and meta-analysis examines available data on the association between hormonal contraception (HC) use, specific types of HC-use and the outcomes of prevalent, incident and recurrent $\mathrm{BV}$.

\section{Methods}

We used the PRISMA statement to guide this systematic review and meta-analysis [19].

\section{Protocol and Registration}

Analysis methods and inclusion criteria were specified in advance and documented in a protocol registered with prospective registration of systematic reviews (PROSPERO), registration number: CRD42013003699 (http://www.crd.york.ac.uk/ PROSPERO/).

\section{Eligibility Criteria}

Types of studies. We searched for all peer-reviewed, English language, studies published before January 2013 that reported an association between BV and HC. Conference abstracts identified in searches were reviewed. Review, editorial and discussion articles were excluded but reference lists were examined.

Types of participants, hormonal contraceptive use and outcome measures. Studies including women of any age investigated for prevalent, incident or recurrent $\mathrm{BV}$, using an established published diagnostic method for BV, such as the Nugent, Amsel, Ison-Hay, Spiegel and modified Amsel methods, were assessed for eligibility. Cohort, cross-sectional and randomised controlled trials (RCTs) were considered for inclusion. Eligible studies had to include a measure of HC-use, exposure to HCs in $\geq 10 \%$ of the study population, and compare HC-users to women not using HC. HC-use included combined oestrogenprogesterone contraception (combined), progesterone-only contraception (POC) and use of an unspecified HC. Studies were ineligible if they were: animal studies, exclusively consisted of postmenopausal or pregnant women, used non-standard BV diagnostic methods, had $<20$ cases of $\mathrm{BV},<10 \%$ of participants using $\mathrm{HC}$, did not have a control/comparator group, or if the control group was exclusively users of intra-uterine devices (IUDs), which have been reported to increase the risk of BV. Studies in which there was no analysis of the association between BV and HC-use presented in the manuscript were excluded. In studies reporting $>1 \mathrm{BV}$ outcome measure, such as prevalent and incident BV, or $>1$ type of HC-type, each outcome and/or HC-type was separately included, if they were mutually exclusive of one another.

\section{Search Strategy}

Studies were predominantly identified by searching electronic databases. Language was limited to English, and any non-English articles that were identified were excluded from the analysis. Our search was applied to the databases Medline (Web of Knowledge
[Pubmed]), Web of Science (Web of Knowledge) and Embase (Ovid) until January $24^{\text {th }} 2013$. We also reviewed reference lists of selected studies for other potentially relevant studies.

\section{Search}

We used the following search terms to search all databases: ((bacterial vaginosis) OR (vaginosis) OR (bacterial infections and vaginitis) $\mathrm{OR}$ (gardnerella)) AND ((hormonal contraceptive) OR (hormone) OR (contraceptive) OR (contraception) OR (oestrogen) OR (progesterone) OR (progestin) OR (Intrauterine device) OR (depot medroxyprogesterone acetate/DMPA) OR (risk factor)) AND Language $=($ English $)$ AND Species $=($ Humans $)$ AND Gen$\operatorname{der}=($ Female $)$.

\section{Study Selection \& Data Collection}

The studies were reviewed and information extracted by two authors independently (LAV \& SW); disagreements were resolved by discussion with CSB and consensus reached. An independent researcher (CEB) identified potential studies from the reference lists of all selected papers for further review. These were then reviewed by LAV \& CSB.

We developed a data extraction sheet (based on the Cochrane Consumers and Communication Review Group's data extraction template) and pilot tested and refined it accordingly. LAV extracted data from included studies and CSB checked extracted data. Consensus for discrepancies was reached by discussion between LAV and CSB, and consultation with JSH and ML as required. Clarification was sought from authors where there was insufficient data to examine the association between HC-use and $\mathrm{BV}$, however this association had clearly been analysed. This included requests for raw data to enable stratification of $\mathrm{BV}$ outcome by HC-use. Eight authors were contacted via email, all responded and four were able to provide additional data.

\section{Data Items}

Information was extracted from each included study on: 1) participant characteristics (age, diagnosis method, geographical location, sample size); 2) recruitment setting (sexual/reproductive health service (SRHS), general community healthcare service (GCHS), population-based study (POP), sex worker service (SWS); 3) number of women positive for $\mathrm{BV}$ and $\mathrm{BV}$ outcome measure (prevalent/incident/recurrent BV); 4) the proportion of women using $\mathrm{HC}$ and type of $\mathrm{HC}$ method(s) used; and 5) study endpoint definition and length of follow-up for longitudinal studies. HC-use was classified as i) combined (combined oral contraceptive pill [COCP], NuvaRing ${ }^{\circledR}$ ) ii) POG (depot medroxyprogesterone acetate [DMPA], implants, injections and norethisterone oenanthate [Net-EN], Mirena ${ }^{\circledR}$ ) and iii) any unspecified-HC (including all HC-types listed above but data unavailable to subclassify as combined or POG).

Studies that utilised duplicated datasets were given the following priority in selection for the meta-analysis to avoid correlation of associations: 1) studies where data was presented stratified by HCtype were given preference over studies with only non-stratified data; 2) studies with adjusted analyses were given preference over those with unadjusted analyses; 3) studies utilising the whole dataset were given priority over sub-studies; and 4) recent publications were used in preference over older publications. Studies that comprised specific populations such as all sex workers, all women who douche, injecting drug users or women diagnosed with concurrent herpes-simplex virus-2 (HSV-2) were included in the analysis. 


\section{Risk of Bias within Individual Studies}

We conducted an analysis of the quality of reporting bias using definitions and classifications based on the MOOSE, STROBE and QATSO guidelines [20-22] as well as criteria published by Caldeira et al [23]. We assessed the risk of bias within observational studies and RCTs and reported on the following parameters; 1) Have the eligibility criteria and the sources and methods of selection of participants been provided (observational and RCT); 2) For longitudinal studies (cohort and RCT), do they describe the methods of follow up; 3) do the authors report a clearly defined and accepted method of outcome assessment; 4) is there a clearly defined exposure (HC-use) assessment; 5) Is HC-use provided stratified data by HC-type; and 6) have outcome adjustments been performed, particularly for a variable consisting of condom use. Allocation, concealment, blinding and randomisation were not relevant as quality measures in manuscripts using data from RCTs because the data contributing to this metaanalysis was derived from the overall trial (data from the arms was combined).

Statistical analyses. We used STATA (Version 12; StataCorp, College Station, TX, USA) for all analyses. For studies that did not report them, 95\% confidence intervals (CIs) were calculated using exact methods. Meta-regression using randomeffects and $\mathrm{p}$-values for linear trend were used to determine pooled BV prevalence estimates and 95\% CIs for eligible studies with sufficient data. To explore variability in study outcome measures (heterogeneity) we hypothesized that the BV prevalence effect size may differ according to the geographical location of the study, the diagnostic method used, and/or the recruitment setting i.e. STI service versus population based studies. Therefore, BV prevalence was stratified by diagnostic method, country group (Europe/UK, Australia/Asia/India, Africa/Middle East, North America, South America) and recruitment setting (SRHS/GHRS/POP/SWS) because of the expected heterogeneity in populations sampled. Given the scope of this review, a summary of this analysis is included in this paper, and further information is available in supplementary material.

The $\mathrm{I}^{2}$ test was used to estimate the proportion of total variability in point estimates attributed to heterogeneity other than that due to chance (values of $<25 \%, 25-75 \%$, and $>75 \%$ representing low, medium, and high heterogeneity, respectively). If the $\mathrm{I}^{2}$ statistic was $<25 \%$, a meta-analysis based on a fixed-effect model was conducted, otherwise the random-effects (re) model was used. If the $\mathrm{I}^{2}$ was $>75 \%$, the studies were not combined.

\section{Primary Summary Measures}

The primary outcome measure was the association between any HC-use and prevalent, incident or recurrent BV. For studies where raw data was provided, odds ratios (ORs) and risk ratios (RRs) were calculated using STATA, otherwise estimates and adjusted estimates were used as reported. The meta-analyses were performed by computing pooled unadjusted/adjusted ORs or unadjusted/adjusted relative RRs using either fixed or randomeffects models. Quantitative analyses were initially performed for the effect of any HC-use and prevalent, incident and recurrent BV separately, and the composite BV outcome measure (prevalent/ incident/recurrent BV), as described below. The secondary outcome measure was the association between specific types of HC-use and each BV outcome measure.

Possible reasons for heterogeneity were explored using prespecified variables to minimise spurious findings. Variables evaluated included i) BV outcome measure by study-design (prevalent, incident and recurrent BV), and ii) HC-type used in prevalent and incident studies (categorized as combined, POC and any unspecified-HC). We calculated pooled summary statistics of estimates using either fixed or random-effects models depending on the $\mathrm{I}^{2}$ statistic, as described above. When statistical heterogeneity was noted, it was evaluated by fitting random-effects metaregression models to the log-transformed individual study point estimates.

We then determined the association between HC-use and a composite BV outcome measure (prevalent/incident/recurrent BV) in addition to our primary and secondary outcome measures described above. To do this, we first converted ORs to RRs in studies where raw data was available using STATA. For four studies in which raw data was not available [24-27], we calculated an approximate RR by extrapolating data provided in the manuscripts to estimate an assumed control group risk and the number of women who were exposed or not exposed to HC. Using the calculated RRs, we then calculated a pooled summary estimate using random-effects models depending on the $\mathrm{I}^{2}$ statistic and evaluated statistical heterogeneity by fitting meta-regression models, as described above.

Sensitivity analyses. Sensitivity analysis was also performed whereby pooled estimates were calculated omitting one study at a time. We then determined the effect of sub-groups of studies on the pooled estimates by re-estimating the overall effect size after omitting the following sub-groups from the meta-analyses: 1) all studies which recruited women to an RCT (regardless of whether or not the associations were derived from baseline pre-screening data or not); 2) studies in which all women were sex workers; 3) studies in which all women were either sex workers, douched, were injecting drug users (IDUs) or had herpes simplex virus 2 (HSV2); 4) studies in which the HC-use comparison group contained women not using any contraception and/or had undergone tubal ligation; and 5) studies which defined their outcome measure as abnormal flora (NS $=4-10)$ instead of $\mathrm{BV}(\mathrm{NS}=7-10)$.

\section{Risk of Bias across Studies}

We assessed the potential presence of publication bias in studies reporting prevalent and incident $\mathrm{BV}$ in separate funnel plots. Asymmetry was statistically evaluated using the Egger's correlation tests by regressing the log of the estimate (unadjusted/adjusted OR or RR) by the $\log$ of the standard error (SE) of the estimate. For studies where raw data was not reported, the SE was estimated based on the width of the reported confidence interval using the formula $(\ln [$ upper limit of $\mathrm{CI}]-\ln [\mathrm{OR}$ or $\mathrm{RR}]) / 1.96$. The few studies reporting the association between HC-use and recurrent $\mathrm{BV}$ were not included in the bias analyses.

\section{Results}

\section{Study Selection}

The review process is outlined in Figure 1 and included papers summarised in Table 1. There were 2566 studies identified from initial searches of Medline $(n=878)$, Web of Science $(n=997)$ and Embase $(n=697), 14$ additional articles were identified by searching reference lists, and one of our own articles that was in press at the time of database searching was included. After removing duplicate articles, 1713 remained of which all titles and abstracts were assessed for potential full text articles to be read; 1211 studies were excluded based on their title and abstract (Figure 1). The full text of 502 articles was reviewed for eligibility criteria, of which there were 59 unique studies that were included in the meta-analysis. Studies were excluded on the basis of: $<20$ cases of BV $(\mathrm{n}=40)$; use of non-standard methods of $\mathrm{BV}$ diagnosis $(\mathrm{n}=15)$, no investigation of HC-use $(\mathrm{n}=223),<10 \%$ of women using $\mathrm{HC}(\mathrm{n}=12)$, there was no analysis of the association between 


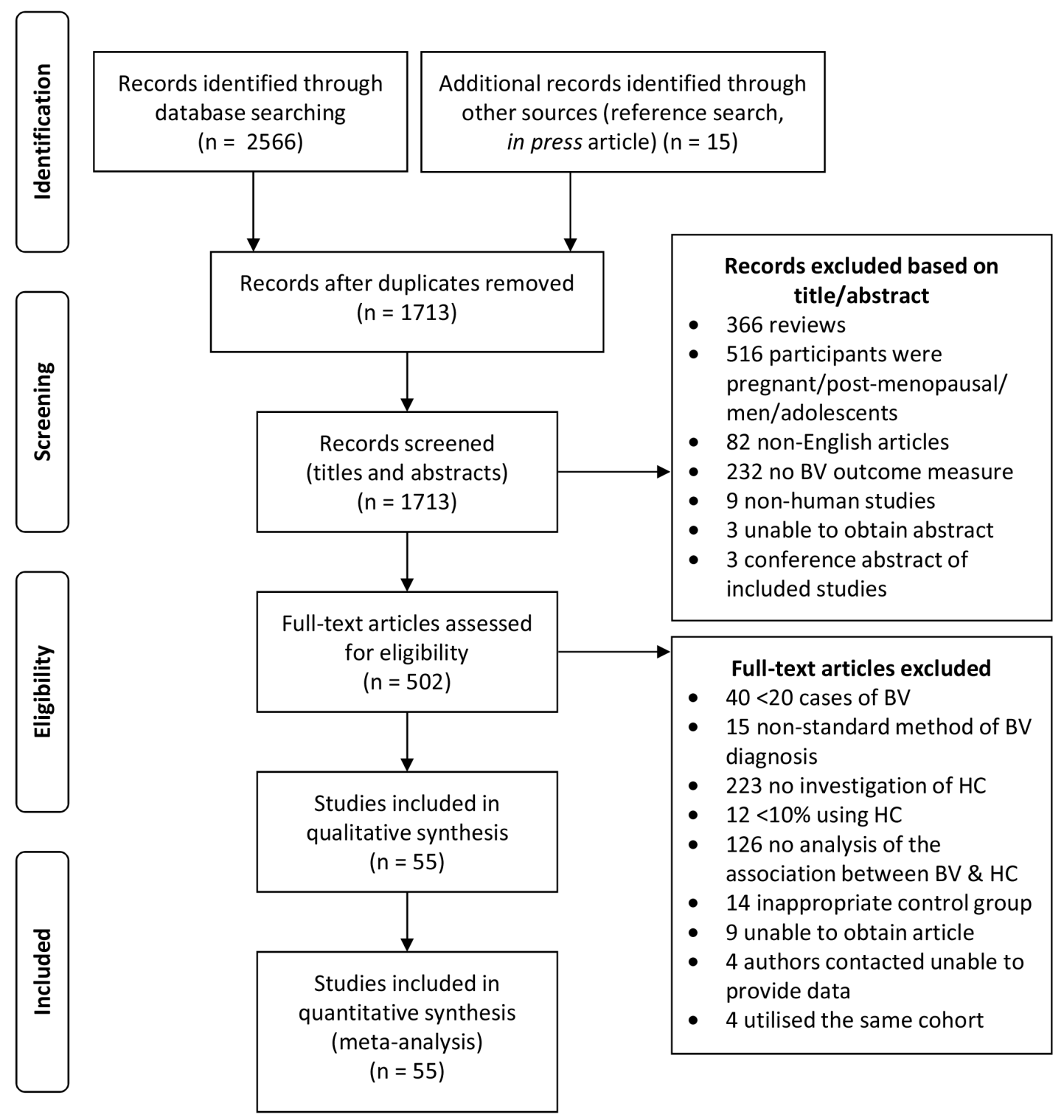

Figure 1. Flowchart demonstrating selection of studies for the systematic review and meta-analysis of the association between hormonal contraceptive (HC) use and bacterial vaginosis (BV). doi:10.1371/journal.pone.0073055.g001

BV and HC-use presented in the manuscript $(\mathrm{n}=126)$, inappropriate/no control group $(\mathrm{n}=14)$, unable to obtain full-text articles $(n=9)$, and contacted authors were unable to provide data $(n=4)$.

Three cohorts of women were utilised for more than one manuscript. To avoid the issue of increased weighting of these cohorts in the meta-analysis we therefore applied our hierarchical selection criteria to select only one publication for each of the three cohorts. The two studies by Ness et al $[28,29]$ utilised data from women enrolled in the GYN Infections Follow-through study. Based on our systematic approach to selection the most recent study was included in our review and meta-analysis. Both Koumans [30] and Hensel [31] reported associations with BV using data from women enrolled in the NHANES cohort. Hensel only reported on a sub-set of the cohort so was excluded and Koumans was included. Finally, Nansel et al 2006 [32], Riggs et al 2007 [16] and two studies by Klebanoff [33,34] all used data from women enrolled in Longitudinal Study of Vaginal Flora cohort to determine the association between HC-use and prevalent and incident BV. Only Riggs stratified HC-use by combined HC-use and POG-use so only this study was included and the others were excluded from our meta-analysis. These exclusions meant only 55 of the 59 unique publications were included in the systematic review and meta-analysis.

\section{Study Characteristics}

All 55 studies included in the analysis were peer-reviewed English language original articles. These studies used the following BV diagnostic methods: standard Amsel methods $(n=18)$, modified Amsel method $(\mathrm{n}=3)$, Nugent method $(\mathrm{n}=30)$, both Amsel and Nugent $(n=1)$, Spiegel method $(n=1)$ and Ison-Hay criteria $(\mathrm{n}=1)$ (Table 1$)$.

Studies using the Nugent method differed in whether they compared women with a NS $=7-10$ (established Nugent definition of $\mathrm{BV})$ to all other participants $[\mathrm{NS}=0-6 \quad(\mathrm{n}=29)]$ or they excluded women with intermediate flora $(\mathrm{NS}=4-6)$ and com- 

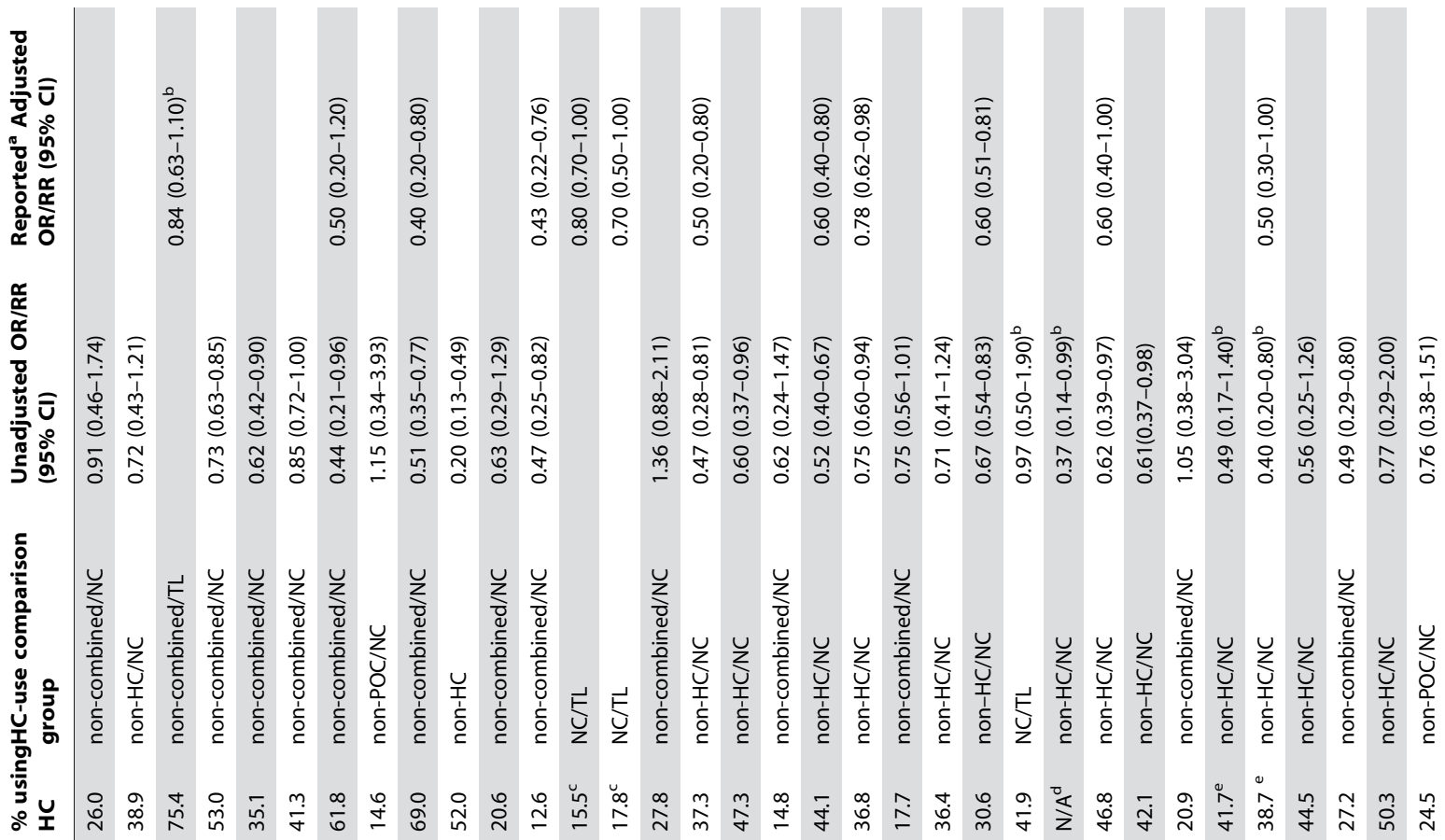

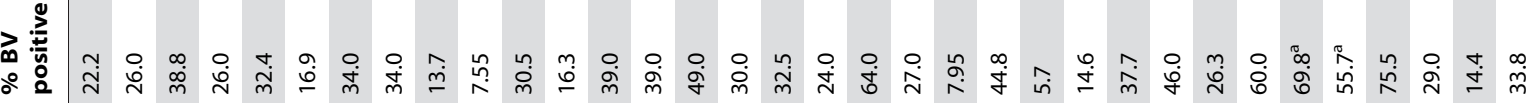
息步

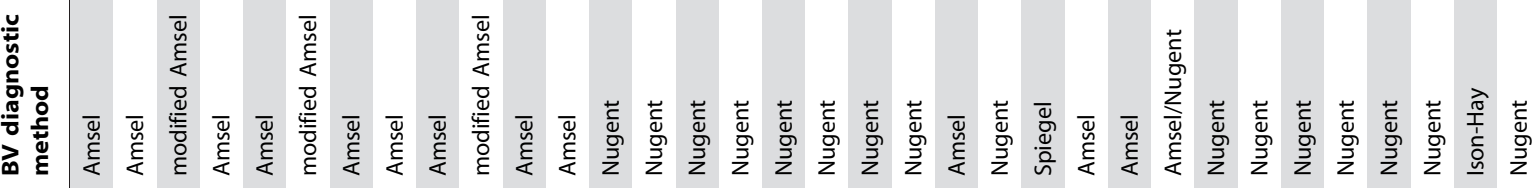
造部

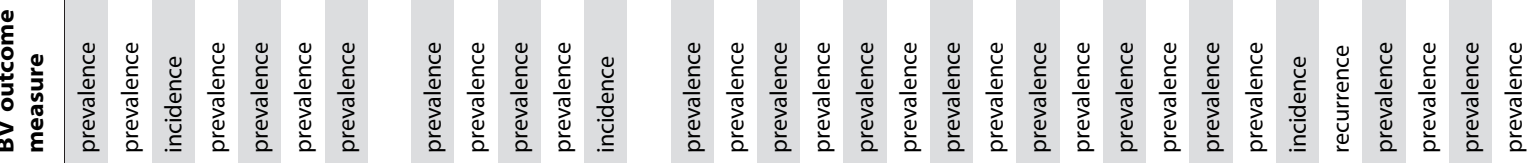
㪯产要

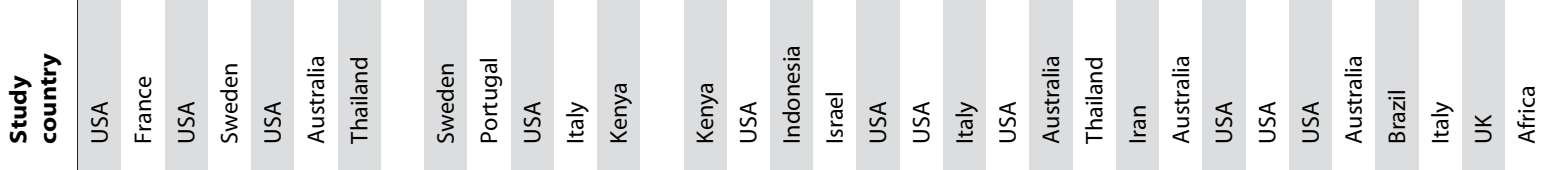
ํํำ 4 .

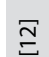

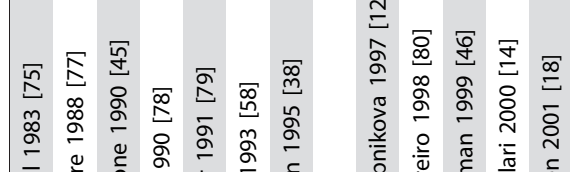

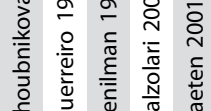

\section{I}

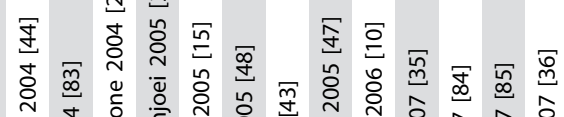

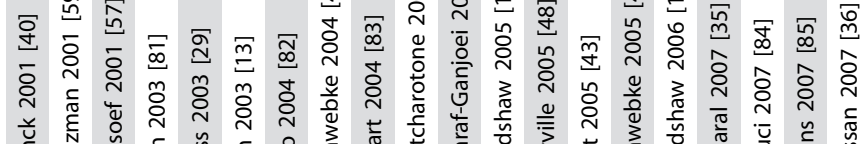




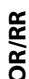

o

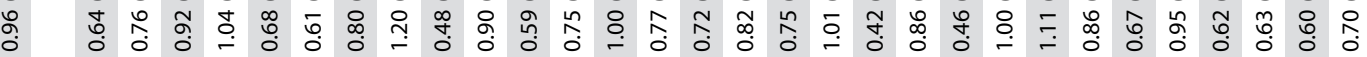

$\frac{\delta}{0}$

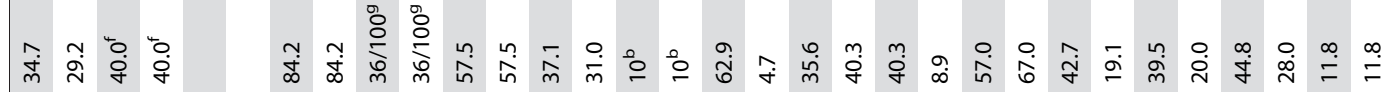

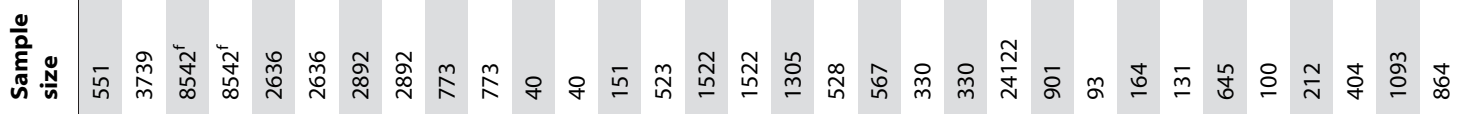

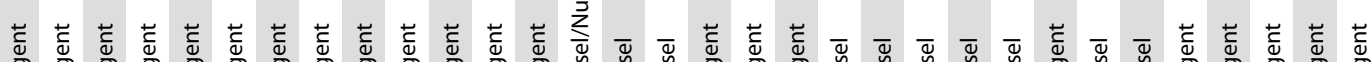

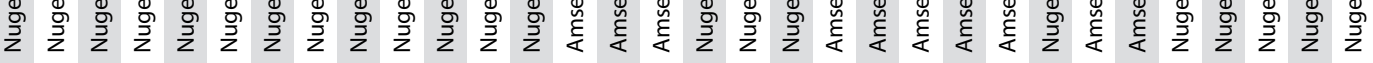

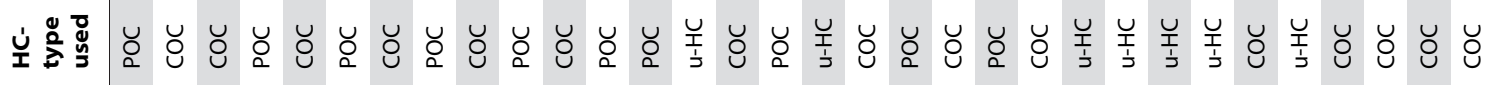

둥

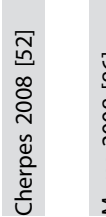

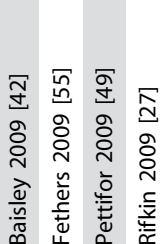

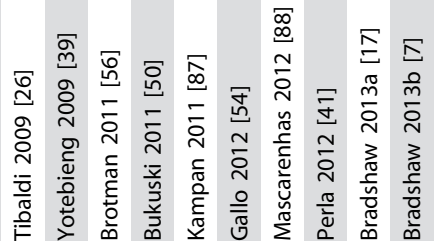




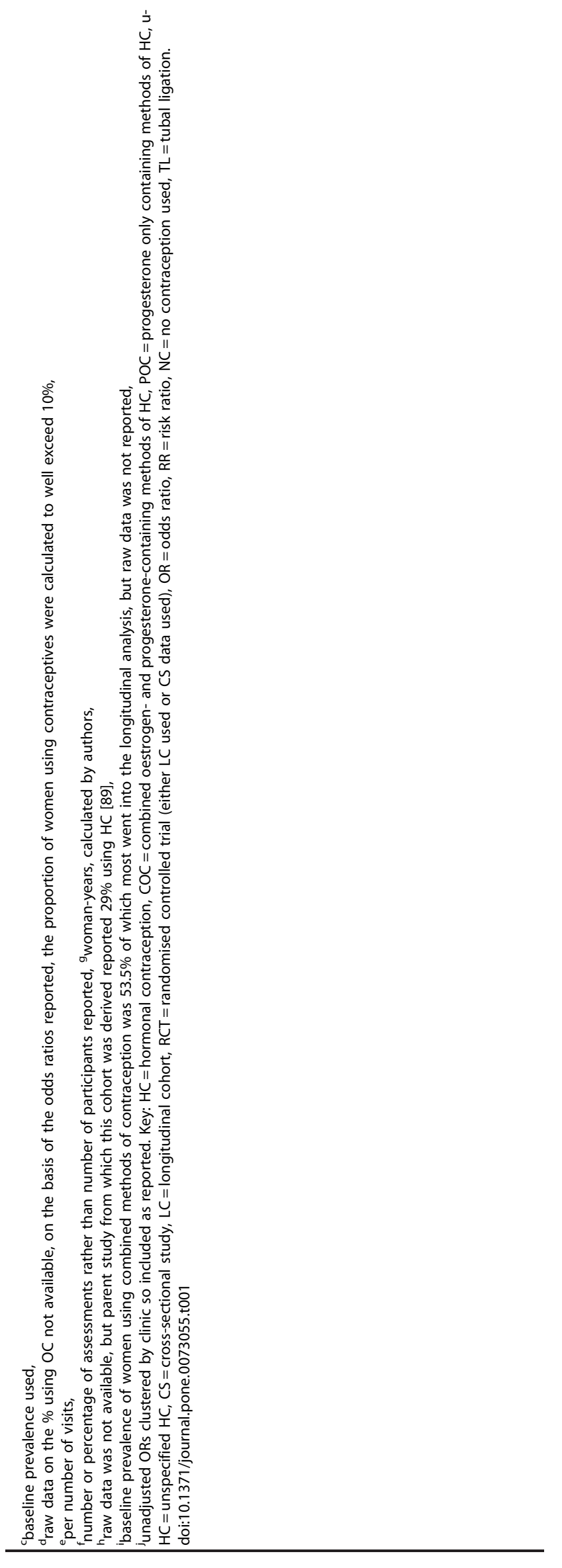

pared NS $=7-10$ to $\mathrm{NS}=0-3 \quad(\mathrm{n}=4)$. Two studies reported comparison of women with abnormal flora (NS $=4-10)$ to normal flora (NS = 0-3) [29,35], and one study defined BV as women with a NS $=7-10$ or NS $=4-6$ with $\geq 3$ Amsel criteria [15]. Data was included as reported in the publications for these studies and did not have significant implications for the association as determined by sensitivity analyses (see below and Table S1, Table S2 and Table S3).

Outcome measure. Studies were able to contribute $>1$ set of data to the analysis if they reported on both combined and POC HC-types separately or $>1 \mathrm{BV}$ outcome (prevalent and incident BV), Table 1. For example, 43 studies contributed 47 associations between HC-use and prevalent BV, 10 contributed 14 associations between $\mathrm{HC}$-use and incident $\mathrm{BV}$, and 4 studies contributed 5 associations between HC-use and recurrent BV. For HC-use, one study reported each association between combined HC-use and POC-use and prevalent, incident and recurrent BV separately [16], and five studies reported each association between BV and combined and POC methods separately. One reported each association between prevalent BV and unspecified HC-use and combined HC-use separately, but only the association of BV and combined HC-use was included [7]. In two of the included studies in which the association between both POC and combined HCuse and prevalent BV [36] and incident BV [37] were investigated separately from the same cohort, only POC-use was included in the meta-analysis, as less than $10 \%$ of the population were using a combined HC method.

The majority of eligible studies were cross-sectional and North American. A minority of studies contained specific population subgroups: in eight all participants were sex workers [18,35-41], in one all had HSV-2 [42], in one all were IDUs [43], and in another all douched [44]. In several studies, participants were predominantly African-American or sub-Saharan African, including eight North American studies [16,27,29,45-48] and nine African studies [18,36,37,39,40,42,49-51]. Although studies where all women were menopausal were excluded, eight included women of an age where some were or may have been peri- or post- menopausal.

Incidence was defined differently in the ten incident BV studies. Time to first BV diagnosis was defined as incident BV in 5 studies, at which point women were censored $[7,45,47,52,53]$. Three of these studies reported 4-monthly follow-up for up to 12 months $[7,47,52]$; Barbone reported monthly follow-up for up to 6 months [45], Rugpao reported 3-monthly visits for 15-24 months [53]. Three studies defined incident BV as a negative visit, followed by a consecutive positive visit $[16,49,54]$, but did not censor at first incident diagnosis, and women could contribute data multiple times during 6-12 months of follow-up. In two studies, multiple and successive $\mathrm{BV}$ diagnoses from an individual were deemed to be new discrete incident cases of BV, however some of these cases may have reflected persistent infection [18,37].

The four studies reporting recurrent BV also used differing study endpoints. Women reached study endpoint if they had a repeat $\mathrm{BV}$ diagnosis or completed follow-up without $\mathrm{BV}$ in the Australian [10,17] and African [50] studies (6 and 2-months of follow-up, respectively). In the North American study [16], recurrent/persistent $\mathrm{BV}$ was defined as having a BV positive visit, followed by a consecutive BV positive visit, so women experiencing more than two consecutive episodes of BV were deemed to have more than one episode of recurrence.

BV prevalence. The median prevalence of $\mathrm{BV}$ was $32.4 \%$ and ranged from $4.7 \%$ in asymptomatic 17-21 year old Australian university students [55] to $66.7 \%$ of American women enrolled in a sub-study [56] (Figure S1). The $\mathrm{I}^{2}$ was $>75 \%$ so studies could not be combined for overall pooled estimates. We stratified BV 
prevalence by: i) geographical location, ii) BV diagnostic method, and iii) recruitment setting. The median $\mathrm{BV}$ prevalence was higher from North America (33.2\% range; 16.1-66.7\%), South America $(47.9 \% ; 20.0-57.5 \%)$ and Africa $(37.7 \% ; 33.8-62.9 \%)$ compared with Europe and the UK (14.4\%; 7.6-29.0\%), Asia and Australia $(16.9 \% ; 4.7-46.0)$ (Table 2, Figure S1), and slightly higher in studies that employed the Nugent $(35.6 \% ; 4.7-62.9 \%)$ compared to Amsel $(22.2 \% ; 7.6-66.7 \%)$ method (Table 2, Figure S2). Stratifying BV prevalence by recruitment setting also demonstrated variation in reported BV prevalence (Table 2, Figure S3). This suggests that variation in $\mathrm{BV}$ prevalence is likely to be due to differences in geographic location, diagnostic methods used, and recruitment settings.

\section{Risk of Bias within Studies}

Most observational studies, including all RCTs, were considered to have adequately reported inclusion and exclusion criteria and to have provided justification for selection of participants. Three studies included all women without specifying specific exclusion criteria $[25,26,57,58]$. For all longitudinal studies, the methods of follow-up were described. Due to our quality criteria for inclusion, all studies clearly defined the method of outcome assessment (Amsel, Nugent, Spiegel or Ison-Hay), with only two studies defining their outcome measure as abnormal flora (NS 4-10) instead of BV (7-10) [29,35], as previously described. The measurement of exposure to $\mathrm{HC}$ in each study was clearly defined, with most studies reporting on current use of $\mathrm{HC}$ at the time of assessment. However, five studies included HC-use as any reported use in a time period that ranged from 3-6 months
[17,43,48,53,59]. Twenty-two studies did not stratify HC-use by combined HC-use or POC-use, and so were included as unspecified HC-use. This unspecified HC group may have been a source of bias within studies as it could have predominantly contained only one specific subtype of HC users. The comparison groups varied between studies, but participants not using $\mathrm{HC}$ were the comparison group in half the studies (Table 1). In 8 studies, the comparison group included women who were not using any contraception and/or who had undergone tubal ligation. Sensitivity analyses excluding studies where the control group was exclusively women not using any contraception were conducted to examine whether this influenced the overall estimates (Tables S1, S2 and S3). No evidence of bias from inclusion of these studies was found. Twenty-nine studies reported results adjusted for at least one confounder. Of these, 23 adjusted for condom use, 13 for age, one for all other variables assessed in the study and one study [14] performed a stepwise logistic regression to identify possible confounders, but did not state which variables were included in the final multiple regression.

Allocation, concealment, blinding and randomisation were not relevant as quality measures in manuscripts using data from RCTs because the data contributing to this meta-analysis was derived from the whole trial (data from the arms was combined), for all but one study which only used women in the placebo arm (vs vaginal presumptive treatment arm) [37]. Importantly, all of the included RCTs are of different interventions and heterogeneous populations. One RCT used pre-trial/screening data so individuals that were analysed in the dataset were not highly selected and subject to rigorous exclusion/inclusion criteria [40]. All others used "ontrial" baseline or longitudinal data, however the trials conducted

Table 2. Assessment of bias: measures of the studies included in the analysis.

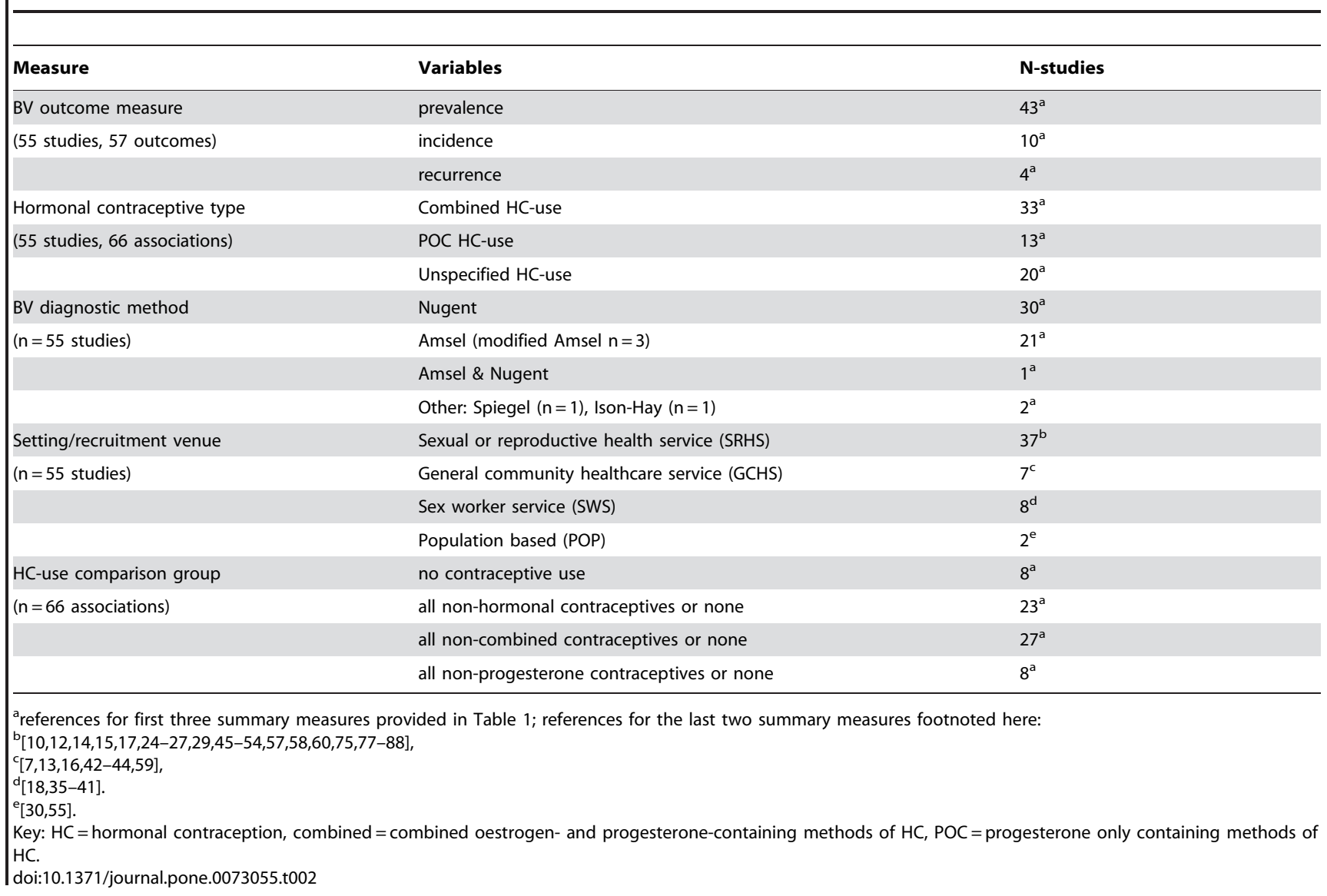


were of a diverse range of interventions and included an antibiotic/probiotic trial [17], spermicide trial [45], presumptive prophylaxis with $1 \mathrm{~g}$ azithromycin [40] or metronidazole and fluconazole [36,37], behavioural intervention [43,60], counselling intervention [39], male partners used an ethanol gel [50], or suppressive acyclovir treatment [42]. The studies that selected specific groups of participants had very diverse selection criteria e.g. all douche [44], all have HSV2 [42], all are IDUs [43]. The highest amount of publication bias was found for potential reporting bias. In 6/11 RCTs results were presented for BV as a pre-specified primary outcome but in $5 / 11$ the primary outcome was a decrease in STIs or risk factors for HIV, and BV analyses were secondary or additional reported outcomes. To address the issue that individuals participating in RCTs may not be entirely representative of the general population and provide a source of within study bias RCTs were excluded as a sub-group in the sensitivity analyses (Tables S1, S2 and S3) and were shown to have no influence on the overall estimates.

\section{Results of Individual Studies}

The association between combined HC-use, POC-use or any unspecified HC-use and prevalent BV was reported in 24,6 and 17 studies, respectively, Table 1 . The average proportion of women using any $\mathrm{HC}$ in studies was $34.4 \%$ (range $10.4 \%-75.4 \%$ ). To reduce the risk of confounding, adjusted ORs/RRs were included where provided. Any HC-use was associated with a significantly reduced prevalence of BV in 19 studies, three studies reported a borderline association with an upper 95\%CI of 1.00 (Table 1, Figure 2), and there was no significant association between any HC-use and BV in 25 studies. When stratified by HC-type, of the 24 studies reporting combined HC-use, nine reported a significantly reduced prevalence of $\mathrm{BV}$, three a borderline association (upper 95\% CI of 1.00) and 12 reported no significant association. Of the six studies investigating POC-use, only two reported a significantly reduced prevalence of BV. Of the 17 studies examining unspecified HC-use, 8 reported a significantly reduced risk of prevalent $\mathrm{BV}$.

Of the 14 incident analyses, 10 showed a reduced risk of incident BV with HC-use $(\mathrm{RR}<1.00)$ (Table 1, Figure 3). Only two studies had a significant association with incident $\mathrm{BV}$, one with combined HC-use and one with POC-use. Two studies had a borderline association with incident $\mathrm{BV}$, again one with combined HC-use and one with POC-use. None of the studies using any unspecified HC-type had a significant association with incident $\mathrm{BV}$. In the five recurrent analyses, four showed a decreased risk of recurrent $\mathrm{BV}$ in HC-users, which was significant in one study reporting combined HC-use and one study reporting POC-use (Table 1, Figure 4).

\section{Synthesis of Overall Results}

Association between BV and hormonal contraceptive use. Due to some studies reporting the association between BV and different types of HC, the 43 prevalence studies contributed 47 datasets or associations, 10 incident studies contributed 14 datasets, and 4 recurrent studies contributed 5 datasets.

Hormonal contraceptive use was associated with a significant reduction in the odds of prevalent $\mathrm{BV}$ (pooled effect size by random-effects $[\mathrm{reES}]=0.68,95 \% \mathrm{CI}: 0.63-0.73, \mathrm{p}<0.001)$, with $27 \%$ of differences between studies due to heterogeneity $\left(\mathrm{I}^{2}=26.5 \%, \mathrm{p}=0.05\right)$, Figure 2. HC-use was also associated with a significant reduction in the relative risk of incident BV (pooled reES $=0.82,95 \%$ CI:0.72-0.92, $\mathrm{p}=0.001$ ), with $54 \%$ of differences due to heterogeneity $\left(\mathrm{I}^{2}=53.6 \%, \mathrm{p}=0.03\right)$, Figure 3 . In the analysis of the effect of HC-use on recurrent BV, HC-use was associated with significantly decreased risk of recurrent BV (pooled reES $=0.69,95 \%$ CI:0.52-0.91, $\mathrm{p}<0.001$ ), with $62 \%$ of differences between studies due to heterogeneity $\left(\mathrm{I}^{2}=61.6 \%, \mathrm{p}=0.03\right)$.

We then stratified type of HC-use (combined/POG/unspecified $\mathrm{HC}$ ) by either prevalent or incident BV (Figures 2 and 3, respectively). With $\leq 2$ studies contributing to the association between recurrent BV and specific HC-types in the meta-analysis, further sub-group analysis was not feasible for recurrent BV. Combined HC-use was associated with a significantly decreased odds of prevalent BV (pooled $\mathrm{ES}=0.72$, 95\%CI:0.66-0.78, $\mathrm{p}<0.001$ ), with $11 \%$ of observed variance due to heterogeneity between studies $\left(\mathrm{I}^{2}=12.5 \%, \mathrm{p}=0.29\right)$. POC-use was also associated with significantly decreased rate of prevalent BV (pooled $\mathrm{ES}=0.69,95 \% \mathrm{CI}: 0.59-0.80, \mathrm{p}<0.001)$, with $23 \%$ of observed differences due to heterogeneity $\left(\mathrm{I}^{2}=22.6 \%, \mathrm{p}=0.26\right)$. Unspecified $\mathrm{HC}$-use was also associated with significantly decreased rate of prevalent BV (pooled reES $=0.64,95 \%$ CI:0.55-0.74, $\mathrm{p}<0.001$ ), with $39 \%$ of observed variance explained by heterogeneity $\left(\mathrm{I}^{2}=39.1 \%, \mathrm{p}=0.05\right)$. Meta-regression analysis revealed no heterogeneity between HC-types (overall $\mathrm{p}=0.43$; combined $\mathrm{v}$ POC $\mathrm{p}=0.82$, combined $\mathrm{v} \mathrm{u}-\mathrm{HC} \mathrm{p}=0.25)$.

When the association between different sub-groups of HC-use and incident BV was examined, both combined HC-use and POC regimens were associated with a decreased risk of incident $\mathrm{BV}$, with pooled reES of 0.85 (95\%CI:0.73-0.98, $\mathrm{p}=0.02)$ and 0.81 (95\%CI:0.65-0.99, $\mathrm{p}=0.04$ ), respectively, Figure 3. Both associations displayed moderate heterogeneity $\left(\mathrm{I}^{2}=47.7 \%, \mathrm{p}=0.08\right.$ and $\mathrm{I}^{2}=64.1 \%, \mathrm{p}=0.02$, respectively). There was only one study reporting the association between unspecified HC-use and incident $\mathrm{BV} \quad(\mathrm{RR}=0.49$, 95\%CI:0.17-1.40). Meta-regression analysis revealed no heterogeneity between HC-types (overall $\mathrm{p}=0.55$; combined $\mathrm{v}$ POC $\mathrm{p}=0.62$, combined $\mathrm{v} \mathrm{u}-\mathrm{HC} \mathrm{p}=0.31$ ).

In the final meta-analysis we examined the effect of any HC-use on the composite outcome of prevalent/incident/recurrent BV. To generate an overall pooled estimate all ORs had to be converted as described in the methods to RRs. As RRs will always show a smaller effect size than ORs, the association between HCuse and the risk of prevalent $\mathrm{BV}$ changed (pooled reES $=0.78$, 95\% CI:0.74-0.82), Figure 4. For the composite outcome, HC-use was associated with a significant reduction in any BV (pooled reES $=0.78,95 \% \mathrm{CI}: 0.74-0.82, \mathrm{p}<0.001)$, Figure 4 . We detected moderate, but significant heterogeneity within this comparison $\left(\mathrm{I}^{2}=53.5 \%, \mathrm{p}<0.001\right)$, suggesting that $54 \%$ of the observed variance between studies can be explained by heterogeneity. Metaregression analysis revealed no heterogeneity between studies reporting prevalent, incident and recurrent BV (overall $\mathrm{p}=0.43$; prevalent $\mathrm{v}$ incident $\mathrm{BV} \mathrm{p}=0.36$; prevalent $\mathrm{v}$ recurrent $\mathrm{BV}$ $\mathrm{p}=0.42$ ).

Sensitivity analyses. We conducted a range of sensitivity analyses to determine the influence certain studies and specific populations had on the overall estimates. The removal of specific populations, RCTs and individual studies did not qualitatively alter associations (Tables S1, S2 and S3). The confidence intervals around the pooled estimates only crossed 1 after exclusion of some sub-groups when looking at the association between HC-types and incident BV, most likely because of the smaller number of studies contributing to these analyses.

\section{Risk of Bias across Studies}

To explore the heterogeneity in the association between HC-use and prevalent or incident BV, funnel plots were drawn using estimates for prevalent and incident BV separately. The funnel plot of the association between any HC-use and prevalent BV 


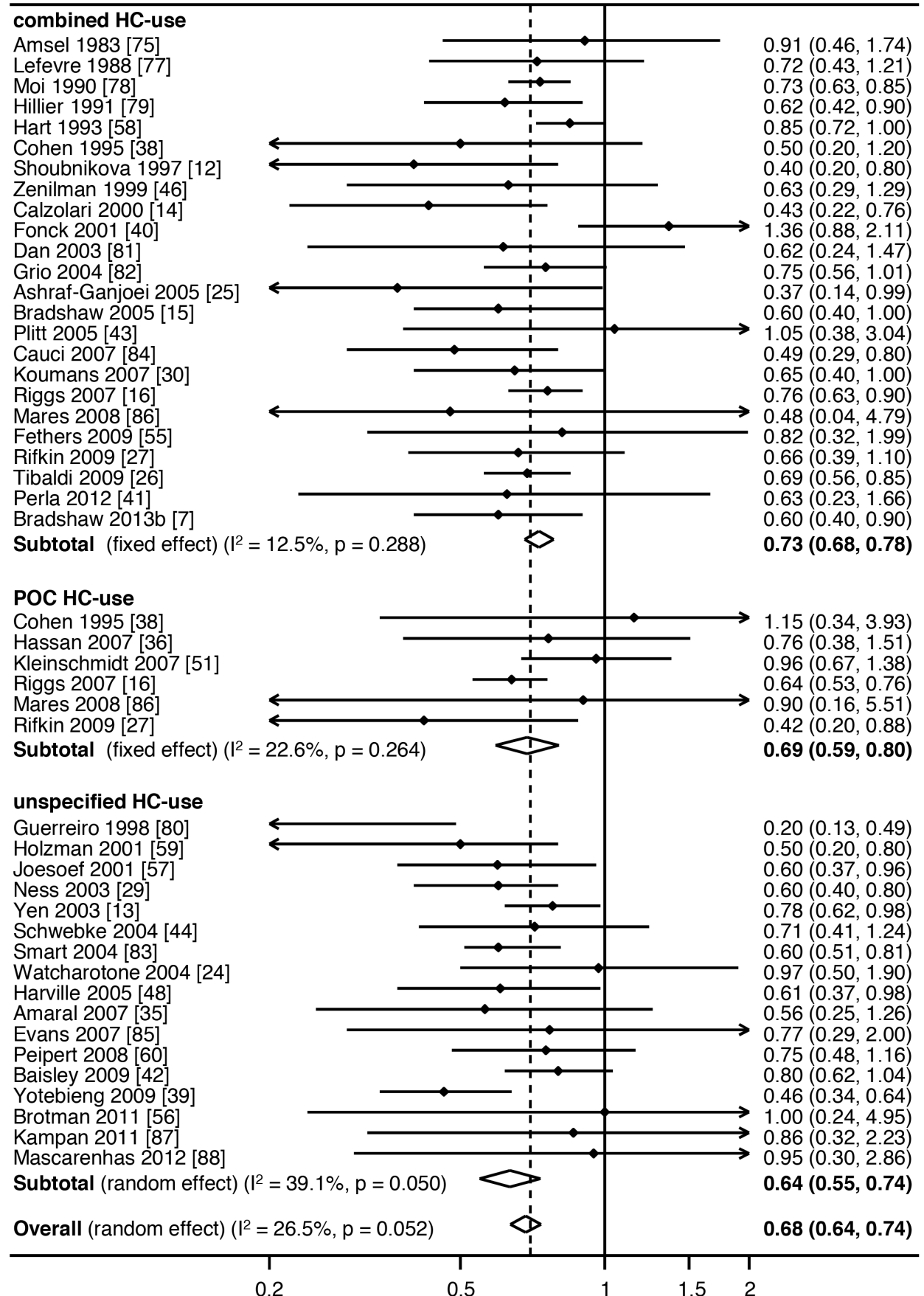

Figure 2. Meta-analysis of the association between hormonal contraceptive (HC) type and prevalent BV. Key: ES=effects size, $\mathrm{Cl}=$ confidence interval, combined $\mathrm{HC}$-use =combined oestrogen- and progesterone-containing methods of $\mathrm{HC}$, $\mathrm{POC}-\mathrm{use}=$ progesterone only containing methods of $\mathrm{HC}$.

doi:10.1371/journal.pone.0073055.g002

showed little asymmetry, with no significant indication for publication bias (Egger's Bias coefficient $=-0.59$, 95\%CI: $-1.31-0.12, \mathrm{p}=0.10)$, Figure 5A. This observation suggests that publication bias is unlikely. The second funnel plot using RR estimates for incident BV showed more asymmetry, particularly due to the lack of smaller studies, Figure 5B. However, there was also no significant indication of publication bias (Egger's Bias coefficient $=-0.36,95 \% \mathrm{CI}:-3.38-2.66, \mathrm{p}=0.80)$. A third funnel plot of the association between any HC-use and composite outcome of any BV showed little asymmetry, again, with no indication of publication bias (Egger's Bias coefficient $=-0.34$, 95\% CI: $-3.31-2.62, p=0.81$ ), Figure 5C.

\section{Discussion}

This systematic review examined the association between use of hormonal contraceptives and detection of $\mathrm{BV}$ and supports the 


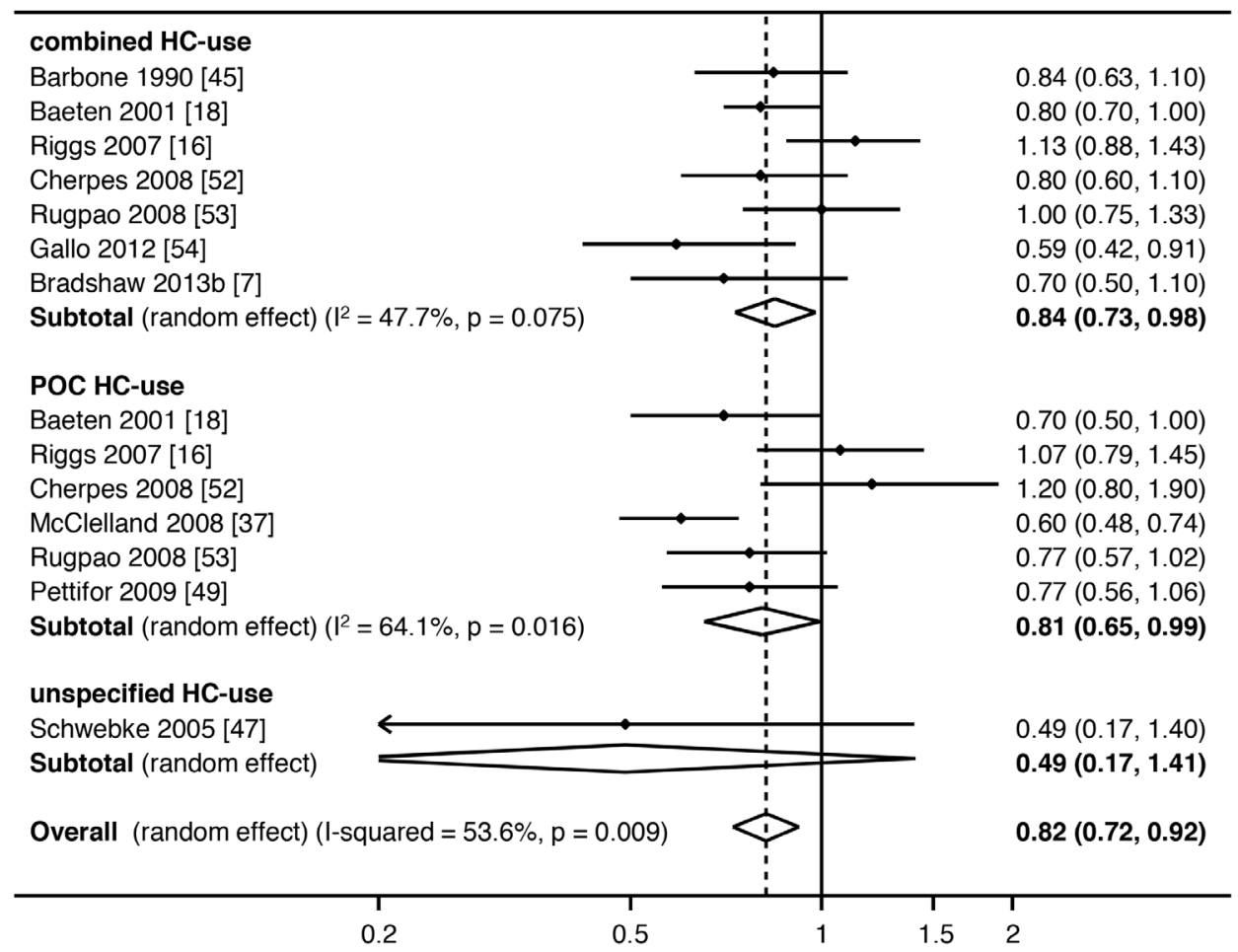

Figure 3. Meta-analysis of the association between hormonal contraceptive (HC) type and incident BV. Key: ES=effects size, $\mathrm{Cl}=$ confidence interval, combined $\mathrm{HC}$-use =combined oestrogen- and progesterone-containing methods of $\mathrm{HC}$, POC-use = progesterone only containing methods of $\mathrm{HC}$.

doi:10.1371/journal.pone.0073055.g003

hypothesis that women using $\mathrm{HC}$ have a decreased risk of $\mathrm{BV}$, compared to women not using a hormonal method of contraception. This negative association was robust and present regardless of the HC-type reported, and was evident across all three BV outcome measures (prevalent, incident and recurrent BV), with the exception of unspecified HC-use and incident BV, for which there was only one study. Most data were available from prevalence compared to incidence studies, and there were few studies examining recurrence; however HC-use was associated with a statistically significant reduced risk of BV for each of these outcomes when separately examined. Hormonal contraceptive use was associated with a $32 \%$ reduction in the odds of prevalent BV (pooled reES $=0.68,95 \% \mathrm{CI}: 0.63-0.73$ ), an 18\% reduction in the relative risk of incident $\mathrm{BV}$ ( $\mathrm{reES}=0.82,95 \% \mathrm{CI}: 0.72-0.92)$, and a $31 \%$ reduction in the risk of recurrent $\mathrm{BV}$ (reES $=0.69$, 95\%CI:0.59-0.91). Unexpectedly, when stratified by reported HC-type, combined HC-use and POC methods were associated with a similar magnitude reduction in prevalent $\mathrm{BV}$ risk. When all estimates were converted to RRs, the meta-analysis showed that individuals using any HC-type had a significant overall reduction in risk of the composite BV outcome (reES $=0.78,95 \% \mathrm{CI}: 0.74$ 0.82). This meta-analysis provides compelling evidence that HCuse influences a woman's risk of $\mathrm{BV}$, with important implications for clinicians and researchers in the field. Importantly, these data encompassed high and low BV prevalence populations in geographically diverse settings, and had a low level of publication bias indicated by funnel plot and Eggers bias tests, and were not influenced by a number of varied sensitivity analyses.

The negative association between HC-use and BV may be somewhat surprising in light of recent data implicating $\mathrm{HC}$, particularly POC, with possible increased risk of HIV transmission [61]. However, over the last 30 years evidence has been emerging from observational studies of a negative association between HCuse and BV. Although the observed association could be due to confounding, it is evident across a large number of studies, many of which attempted to control for the confounding effects of behaviours, including condom use and recent sexual practices. A number of possible biological mechanisms may underlie this observed reduction in $\mathrm{BV}$ risk. One plausible hypothesis, that is more relevant to oestrogen-containing contraceptives, is that they may reduce the risk of $\mathrm{BV}$ by increasing the glycogen-content of epithelial cells, which is metabolised to lactic acid by epithelial cells and lactobacilli. Lactic acid is thought to be the primary vaginal acidifier and a known potent inhibitor of BV[62-64]. Higher lactic acid abundance has been reported in women with a vaginal microbiome dominated by L.crispatus, which appear able to produce more lactic acid than other species [65]. Furthermore, lactic acid has also been shown to elicit a favourable cytokine response in the female genital tract [66], which may further assist in reducing the risk of $\mathrm{BV}$.

While the glycogen-lactic acid theory may explain a protective effect from oestrogen, it seems unlikely to be relevant to progesterone-only contraceptives, which often result in an oestrogen-deficient state. Interestingly, however, both progesterone and oestrogen appear to regulate a number of important immune mechanisms in genital tract epithelial and immune cells, with mid-cycle immunological suppression allowing for fertilization and pregnancy. There is direct and indirect cyclical regulation of soluble immune mediators, such as immunoglobulins (in particular IgA and IgG), secretory leukocyte protease inhibitor 
prevalence

Amsel 1983 [75]

Lefevre 1988 [77]

Moi 1990 [78]

Hillier 1991 [79]

Hart 1993 [58]

Cohen 1995 [38]

Cohen 1995 [38]

Shoubnikova 1997 [12]

Guerreiro 1998 [80]

Zenilman 1999 [46]

Calzolari 2000 [14]

Fonck 2001 [40]

Holzman 2001 [59]

Joesoef 2001 [57]

Dan 2003 [81]

Ness 2003 [29]

Yen 2003 [13]

Grio 2004 [82]

Schwebke 2004 [44]

Smart 2004 [83]

combined

combined

combined

combined

combined

combined

POC

combined

$\mathrm{u}-\mathrm{HC}$

combined

combined

combined

$\mathrm{u}-\mathrm{HC}$

$\mathrm{u}-\mathrm{HC}$

combined

$\mathrm{u}-\mathrm{HC}$

$\mathrm{u}-\mathrm{HC}$

combined

$\mathrm{u}-\mathrm{HC}$

$\mathrm{u}-\mathrm{HC}$

Watcharotone 2004 [24] U-HC

Ashraf-Ganjoei 2005 [25] combined

Bradshaw 2005 [15]

Harville 2005 [48]

Plitt 2005 [43]

Amaral 2007 [35]

Cauci 2007 [84]

Evans 2007 [85]

Hassan 2007 [36]

Kleinschmidt 2007 [51]

Koumans 2007 [30]

Riggs 2007 [16]

Riggs 2007 [16

Mares 2008 [86]

Mares 2008 [86]

Peipert 2008 [60]

Baisley 2009 [42]

Fethers 2009 [55]

Rifkin 2009 [27]

Rifkin 2009 [27]

Tibaldi 2009 [26]

Yotebieng 2009 [39]

Brotman 2011 [56]

Kampan 2011 [87]

Mascarenhas 2012 [88]

Perla 2012 [41]

combined

$\mathrm{u}-\mathrm{HC}$

combined

$\mathrm{u}-\mathrm{HC}$

combined

$\mathrm{u}-\mathrm{HC}$

POC

POC

combined

combined

POC

combined

POC

$\mathrm{u}-\mathrm{HC}$

$\mathrm{u}-\mathrm{HC}$

combined

combined

POC

combined

$\mathrm{u}-\mathrm{HC}$

$\mathrm{u}-\mathrm{HC}$

$\mathrm{u}-\mathrm{HC}$

Bradshaw 2013b [7]

combined

combined

Subtotal (random effect) $\left(I^{2}=53.4 \%, p<0.001\right)$

\section{incidence}

Barbone 1990 [45]

Baeten 2001 [18]

Baeten 2001 [18

Schwebke 2005 [47]

Riggs 2007 [16]

Riggs 2007 [16

Cherpes 2008 [52

Cherpes 2008 [52]

McClelland 2008 [37]

Rugpao 2008 [53]

Rugpao 2008 [53]

Pettifor 2009 [49]

Gallo 2012 [54]

Bradshaw 2013b [7]

Subtotal (random effect) $\left(I^{2}=53.6 \%, p=0.009\right)$

recurrence

Bradshaw 2006 [10]

Riggs 2007 [16]

Riggs 2007 [16]

Bukusi $2011[50]$

Bradshaw 2013a [17]

Subtotal (random effect) $\left(I^{2}=61.4 \%, p=0.035\right)$

Overall (random effect) $\left(I^{2}=53.5 \%, p<0.001\right)$ combined

combined

POC

$\mathrm{u}-\mathrm{HC}$

combined

POC

combined

POC

POC

combined

POC

POC

combined

combined

$\mathrm{u}-\mathrm{HC}$

combined

$\mathrm{POC}$

$\mathrm{u}-\mathrm{HC}$

combined

)

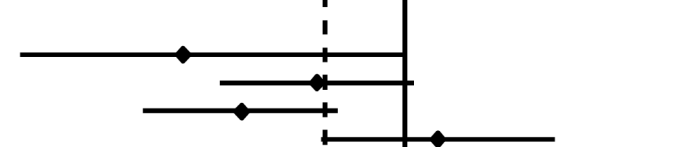

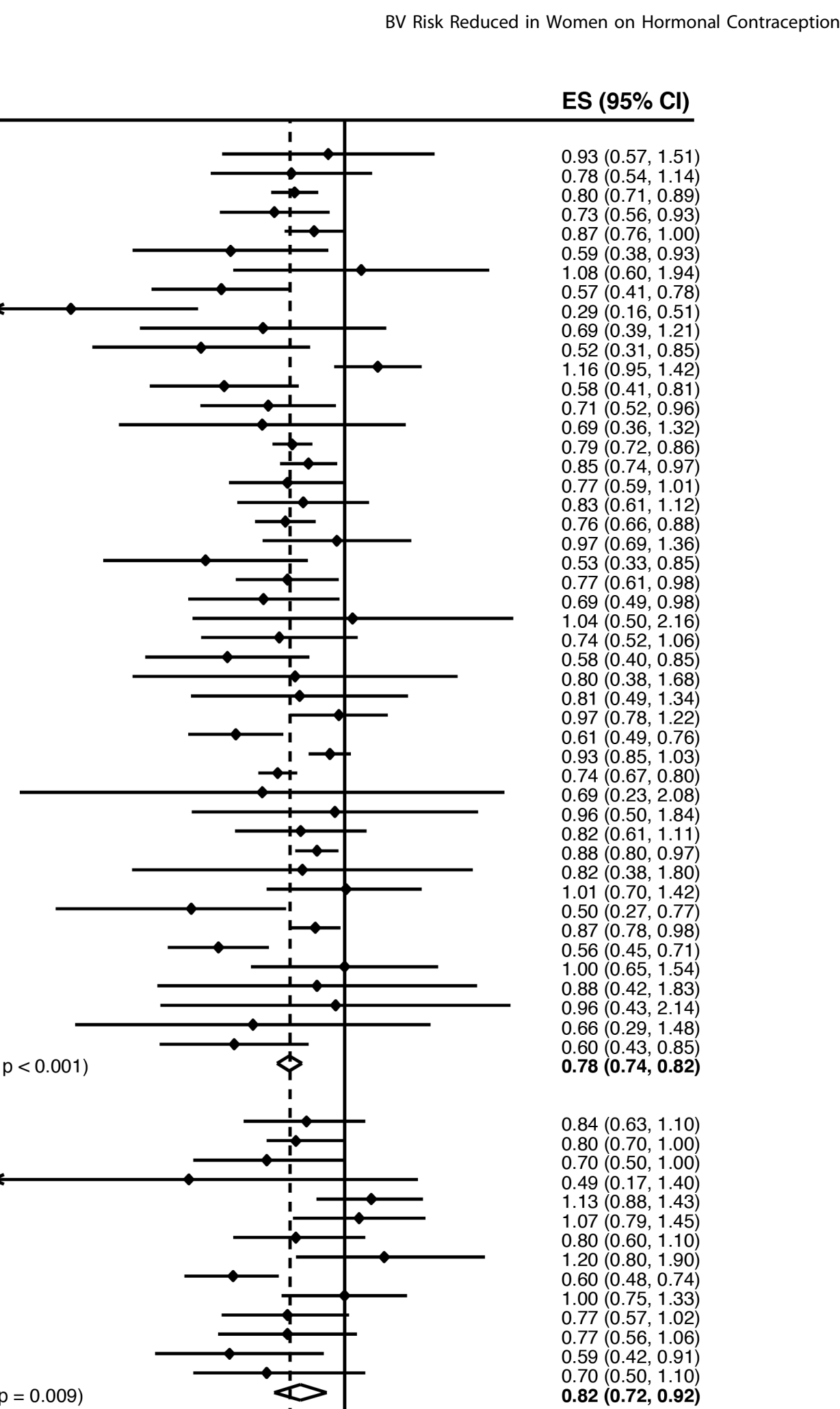
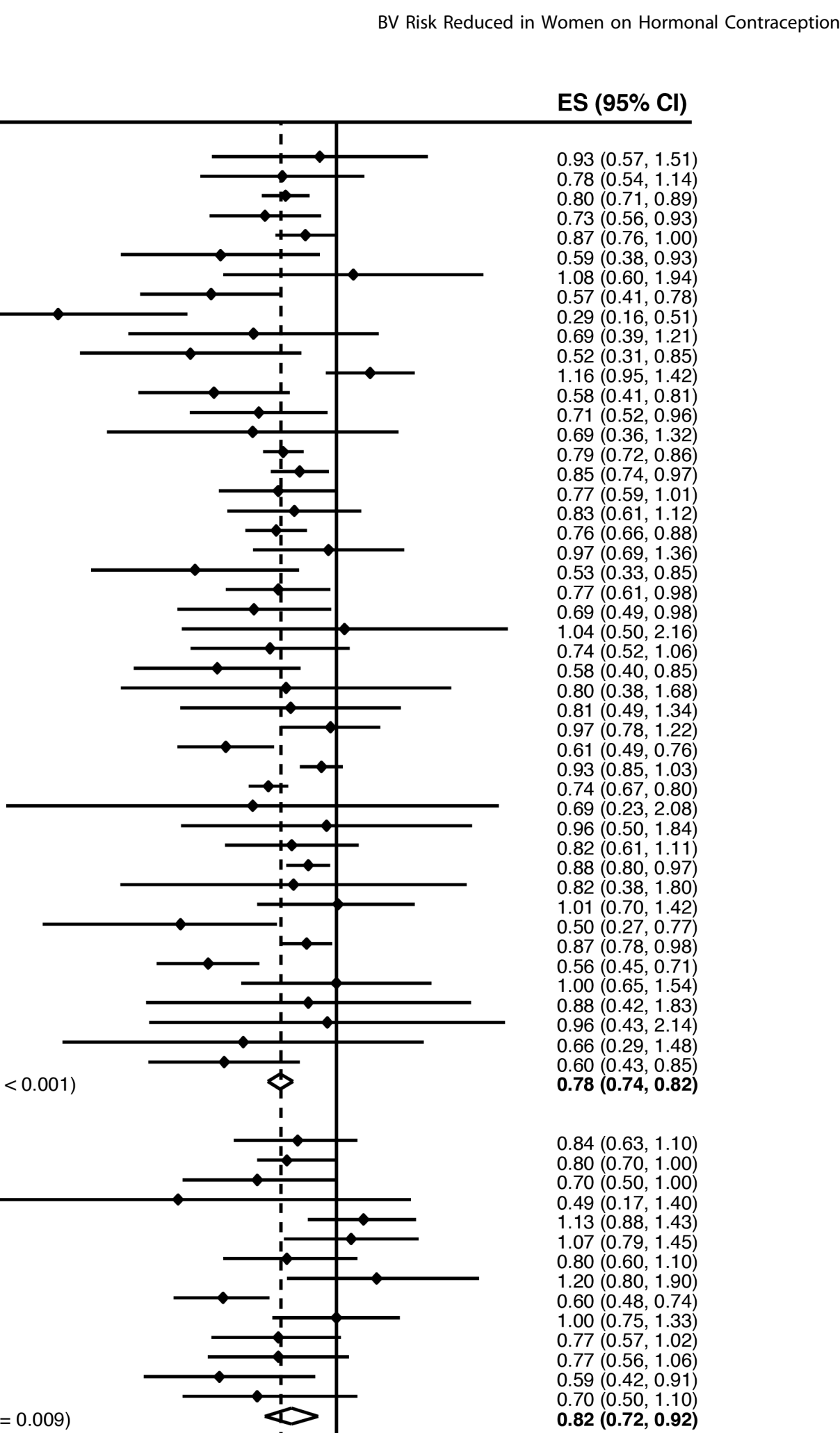

$0.50(0.30,1.00)$

$0.76(0.56,1.03)$

$0.60(0.44,0.81)$

$1.11(0.77,1.60)$

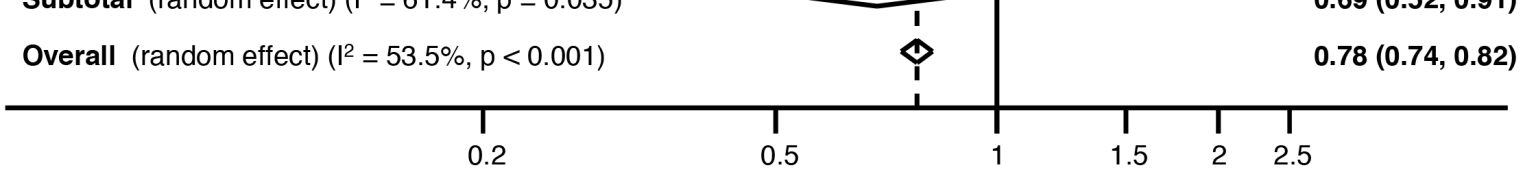

$0.52(0.34,0.81)$

$0.69(0.52,0.91)$

$0.78(0.74,0.82)$ 
Figure 4. Meta-analysis of the association between specified and unspecified hormonal contraceptive (HC) use and BV outcome, stratified by prevalent, incident or recurrent BV. Key: $\mathrm{ES}=$ effects size, $\mathrm{Cl}=$ confidence interval, combined=combined oestrogen- and progesterone-containing methods of $\mathrm{HC}, \mathrm{POC}=$ progesterone only containing methods of $\mathrm{HC}, \mathrm{u}-\mathrm{HC}=$ unspecified $\mathrm{HC}$. doi:10.1371/journal.pone.0073055.g004

(SLPI), and defensins, which have antimicrobial actions against bacteria, fungi and viruses. Both sex steroids also influence recruitment of lymphocytes, natural killer cells, macrophages and Langerhans cells and production of cytokines $[67,68]$. The actions of these hormones are complex and appear to vary depending on concentration, and to also differ between the vagina and the endometrium [67]. Oestrogen exerts pro-inflammatory effects at low concentrations, and anti-inflammatory effects at high concentrations [69]. The concentrations and cyclical pattern of expres-

A

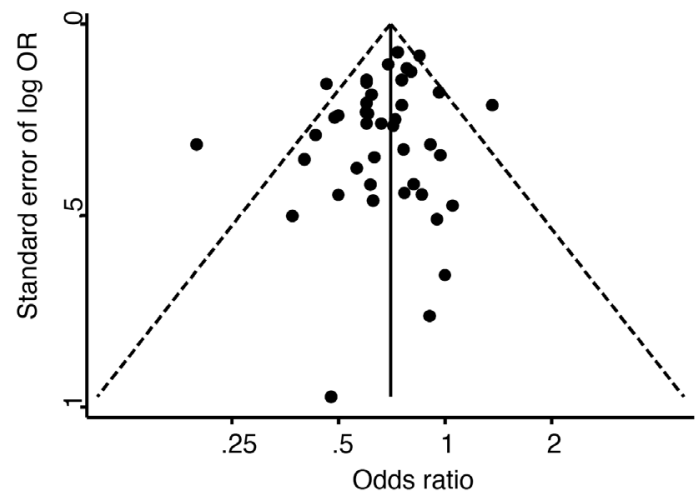

B

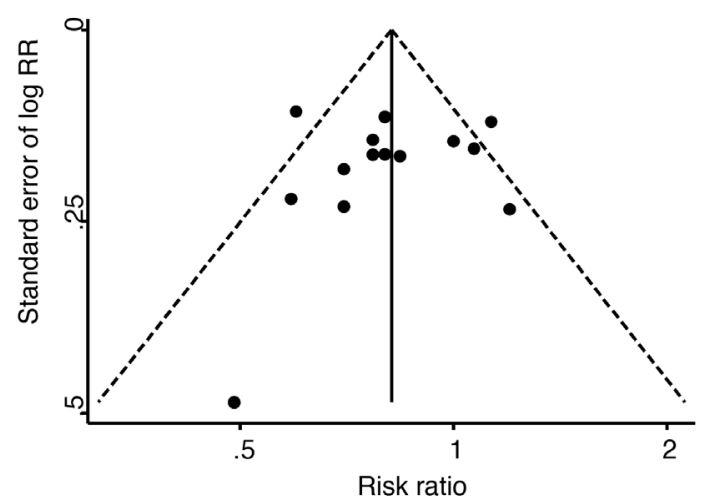

C

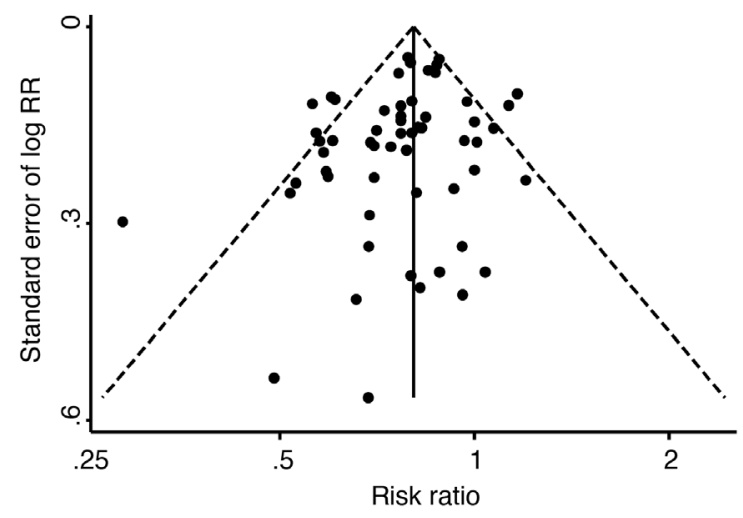

Figure 5. Funnel plots demonstrating the potential presence of publication bias in studies reporting A) prevalent BV, B) incident BV and C) the composite outcome of any BV. Key: $\mathrm{OR}=$ odds ratio, $\mathrm{RR}=$ risk ratio.

doi:10.1371/journal.pone.0073055.g005 sion of $\beta$-Defensins have been reported to differ during the phases of the menstrual cycle and between combined HC users compared to non-users [70].

A further mechanism by which $\mathrm{HC}$, particularly progesteronecontaining $\mathrm{HC}$, may protect against $\mathrm{BV}$ is by reducing the frequency of menstruation, and therefore the volume and presence of haemoglobin in the genital tract. A number of studies have reported that $\mathrm{BV}$ is detected more commonly at the beginning of the menstrual cycle when oestradiol levels are lowest $[15,59,71,72]$. Iron is essential for growth for most bacteria, including BVAB. Experiments have shown that G.vaginalis is capable of both utilizing iron-containing compounds from sources including haemoglobin, and producing siderophores to acquire iron from the environment [73]. Furthermore, quantities of L.jensenii and L.crispatus have been shown to decrease and G.vaginalis concentrations to increase with the onset of menses [74]. It is possible that through reduction in menstrual loss, HC-use influences susceptibility to colonization with $\mathrm{BVAB}$, and that this effect may be particularly relevant to progesterone-only methods that commonly produce amenorrhoea.

Clearly, further research is needed to understand the complex multifaceted effects of both oestrogen and progesterone on the vaginal environment. However, one could reasonably postulate that increased and sustained circulating levels of sex hormones could potentially act in a number of favourable ways to promote and support a healthy vaginal state and reduce the risk of BV. This may include facilitating growth of protective Lactobacillus species, and supporting sustained high levels of lactic acid and favourable alterations to immune mechanisms in the female genital tract, that promotes vigorous host responses and clearance of BVAB. While more research is needed to disentangle the biological mechanisms that may underlie this association, clearly only a randomised controlled trial (RCT) will determine whether HC-use does exert a protective effect against BV.

A number of important limitations were present in this metaanalysis. First, the meta-analysis was limited to published studies, which could overestimate the overall estimates if there has been publication bias resulting from the tendency to publish and present only statistically significant findings. We only searched studies which were published in English, which may limit the generalizability of our findings; however included studies represented women in all continents and from diverse ethnicities. Importantly, no evidence of publication bias was seen in either funnel plot or in the Eggers test for bias, and in a number of studies where raw data was presented, we included derived associations that were not mentioned in the manuscript. A potential limitation is the inclusion of clinical trials and quite specific sub-populations. While this may have also contributed to bias, we conducted sensitivity analyses and showed that their inclusion did not significantly affect the overall effect size. Although we included adjusted estimates where possible, unmeasured confounding may have contributed to the pooled estimates i.e. there may have been other unmeasured biases contributing to women's choice of HC, which was not adjusted for in analyses and may have resulted in an overestimation of the effect. One of the strengths of this metaanalysis was that it included highly diverse studies from many different geographical locations, and women with diverse risks from various recruitment settings, but there were more women recruited from sexual/reproductive health services compared to 
broader population-based studies. This may somewhat limit the generalizability of the findings, and could be a source of bias, however, as the negative association is robust across these heterogeneous studies, this indicates the impact of selection bias is minimal. A significant proportion of studies did not specify type of HC-use. This may have disproportionately affected the associations between POC-use and BV outcomes in for instance African settings, and combined HC-use in developed nation settings, where each of these methods is, respectively, more commonly used. Overall, however, this is likely to have limited impact on the pooled estimates. Finally, the control groups varied between studies and often contained IUD-users, users of other HC-types and condom users. IUD-use, which predominantly reflected non-hormonal IUDs, has importantly been associated with increased risk of BV [75]. For this reason, we excluded any studies that exclusively had IUD-users as the control population as this would lead to an overestimation of the effect, but importantly, for the majority of other studies, IUD-users represented only a minority of the control population. It is reasonable to assume that many HC-users may use condoms less consistently than non-HC users. However, a previous meta-analysis has shown that condom use is associated with a $20 \%$ reduced risk for BV [76], and therefore the inclusion of a greater proportion of consistent condom users in control populations, is more likely to underestimate, rather than overestimate, an observed protective effect of $\mathrm{HC}$ against BV. Importantly, we included ratios that had been adjusted for condom use when provided. The most striking observation from these data is that the negative association between $\mathrm{HC}$-use and $\mathrm{BV}$ was robust and consistent when stratified by HC-type and across the three outcome measures.

In conclusion, this meta-analysis demonstrates a negative association between $\mathrm{HC}$-use and the risk of $\mathrm{BV}$, and raises the tantalizing potential role of exogenous steroid hormones in influencing the vaginal environment in a protective manner against the development of BV. With over $50 \%$ of women experiencing BV recurrence following first-line antibiotic therapies, and no significant improvement in the management of BV in the last 20 years, identifying potential modifiable sexual and contraceptive practices that influence susceptibility to infection and recurrence are integral to progressing prevention and management approaches for this important and common genital tract infection. Crucially, there are no data from RCTs evaluating a hormonal intervention, and the mechanism(s) by which hormonal contraception may exert a protective effect against BV requires further investigation.

\section{References}

1. Atashili J, Poole C, Ndumbe PM, Adimora AA, Smith JS (2008) Bacterial vaginosis and HIV acquisition: a meta-analysis of published studies. AIDS 22: 1493-1501.

2. Martin HL, Richardson BA, Nyange PM, Lavreys L, Hillier SL, et al. (1999) Vaginal lactobacilli, microbial flora, and risk of human immunodeficiency virus type 1 and sexually transmitted disease acquisition. J Infect Dis 180: 1863-1868.

3. Hay PE, Morgan DJ, Ison CA, Bhide SA, Romney M, et al. (1994) A longitudinal study of bacterial vaginosis during pregnancy. Br J Obstet Gynaecol 101: 1048-1053

4. Hillier SL, Nugent RP, Eschenbach DA, Krohn MA, Gibbs RS, et al. (1995) Association between bacterial vaginosis and preterm delivery of a low-birthweight infant. The Vaginal Infections and Prematurity Study Group. N Engl J Med 333: 1737-1742.

5. Wiesenfeld HC, Hillier SL, Krohn MA, Landers DV, Sweet RL (2003) Bacterial vaginosis is a strong predictor of Neisseria gonorrhoeae and Chlamydia trachomatis infection. Clin Infect Dis 36: 663-668.

6. Allsworth JE, Peipert JF (2007) Prevalence of bacterial vaginosis: 2001-2004 national health and nutrition examination survey data. Obstet Gynecol 109: 114-120.

7. Bradshaw CS, Walker J, Fairley CK, Chen MY, Tabrizi SN, et al. (2013) Prevalent and incident bacterial vaginosis are associated with sexual and contraceptive behaviours in young Australian women. PLoS One 8: e57688.

\section{Supporting Information}

Figure S1 Prevalence of bacterial vaginosis (BV) in prevalence studies, stratified by geographical location. Key: $\mathrm{nNUM}=$ population size, $\mathrm{CI}=$ confidence interval (TIF)

Figure S2 Prevalence of bacterial vaginosis $(\mathrm{BV})$ in prevalence studies, stratified by BV diagnostic method (Amsel/modified Amsel method compared to Nugent method). Three studies used other methods (Ison-Hay, Spiegal and one study that used both Amsel and Nugent methods) and were not included in this figure. Key: $\mathrm{nNUM}=$ population size (TIF)

Figure S3 Prevalence of bacterial vaginosis (BV) in prevalence studies, stratified by recruitment setting. Key: $\mathrm{nNUM}=$ population size, $\mathrm{SRHS}=$ sexual or reproductive health service, GCHS = general community healthcare service, $\mathrm{SWS}=$ sex worker service, $\mathrm{POP}=$ population based

(TIF)

Table S1 Sensitivity analyses of all prevalent BV studies included in the meta-analysis, stratified by hormonal contraceptive type used.

(DOCX)

Table S2 Sensitivity analyses of all incident BV studies included in the meta-analysis, stratified by hormonal contraceptive type used.

(DOCX)

Table S3 Sensitivity analyses of all studies included in the meta-analysis, stratified by BV outcome measure (prevalent, incident, recurrent BV).

(DOCX)

\section{Acknowledgments}

The authors would like to acknowledge the assistance of Clare E Bellhouse (CEB) with the identification of studies to be reviewed for inclusion.

\section{Author Contributions}

Conceived and designed the experiments: LAV CSB JSH ML CKF SNT. Performed the experiments: LAV SW CSB JSH ML. Analyzed the data: LAV CSB JSH ML. Wrote the paper: LAV CSB JSH ML CKF SNT SW.

8. Koumans EH, Markowitz LE, Hogan V (2002) Indications for therapy and treatment recommendations for bacterial vaginosis in nonpregnant and pregnant women: a synthesis of data. Clin Infect Dis 35: S152-172.

9. Oduyebo OO, Anorlu RI, Ogunsola FT (2009) The effects of antimicrobial therapy on bacterial vaginosis in non-pregnant women. Cochrane Database Syst Rev: CD006055.

10. Bradshaw CS, Morton AN, Hocking JS, Garland SM, Morris MB, et al. (2006) High recurrence rates of bacterial vaginosis over the course of 12 months after oral metronidazole therapy and factors associated with recurrence. J Infect Dis 193: $1478-1486$.

11. Bradshaw CS, Pirotta M, De Guingand D, Hocking JS, Morton AN, et al. (2012) Efficacy of oral metronidazole with vaginal clindamycin or vaginal probiotic for bacterial vaginosis: randomised placebo-controlled double-blind trial. PLoS One 7: e34540.

12. Shoubnikova M, Hellberg D, Nilsson S, Mardh PA (1997) Contraceptive use in women with bacterial vaginosis. Contraception 55: 355-358.

13. Yen S, Shafer M-A, Moncada J, Campbell CJ, Flinn SD, et al. (2003) Bacterial vaginosis in sexually experienced and non-sexually experienced young women entering the military. Obstet Gynecol 102: 927-933.

14. Calzolari E, Masciangelo R, Milite V, Verteramo R (2000) Bacterial vaginosis and contraceptive methods. Int J Gynaecol Obstet 70: 341-346. 
15. Bradshaw CS, Morton AN, Garland SM, Morris MB, Moss LM, et al. (2005) Higher-risk behavioral practices associated with bacterial vaginosis compared with vaginal candidiasis. Obstet Gynecol 106: 105-114.

16. Riggs M, Klebanoff M, Nansel T, Zhang J, Schwebke J, et al. (2007) Longitudinal association between hormonal contraceptives and bacterial vaginosis in women of reproductive age. Sex Transm Dis 34: 954-959.

17. Bradshaw CS, Vodstrcil LA, Hocking JS, Law M, Pirotta M, et al. (2013) Recurrence of bacterial vaginosis is significantly associated with posttreatment sexual activities and hormonal contraceptive use. Clin Infect Dis 56: 777-786.

18. Baeten JM, Nyange PM, Richardson BA, Lavreys L, Chohan B, et al. (2001) Hormonal contraception and risk of sexually transmitted disease acquisition: results from a prospective study. Am J Obstet Gynecol 185: 380-385.

19. Moher D, Liberati A, Tetzlaff J, Altman DG (2009) Preferred reporting items for systematic reviews and meta-analyses: the PRISMA statement. PLoS Med 6: e1000097.

20. Wong WC, Cheung CS, Hart GJ (2008) Development of a quality assessment tool for systematic reviews of observational studies (QATSO) of HIV prevalence in men having sex with men and associated risk behaviours. Emerg Themes Epidemiol 5: 23.

21. von Elm E, Altman DG, Egger M, Pocock SJ, Gotzsche PG, et al. (2007) The Strengthening the Reporting of Observational Studies in Epidemiology (STROBE) statement: guidelines for reporting observational studies. PLoS Med 4: e296.

22. Stroup DF, Berlin JA, Morton SC, Olkin I, Williamson GD, et al. (2000) Metaanalysis of observational studies in epidemiology: a proposal for reporting. Metaanalysis Of Observational Studies in Epidemiology (MOOSE) group. Jama 283: 2008-2012.

23. Caldeira D, Alarcao J, Vaz-Carneiro A, Costa J (2012) Risk of pneumonia associated with use of angiotensin converting enzyme inhibitors and angiotensin receptor blockers: systematic review and meta-analysis. BMJ 345: e4260.

24. Watcharotone W, Sirimai K, Kiriwat O, Nukoolkarn P, Watcharaprapapong O, et al. (2004) Prevalence of bacterial vaginosis in Thai women attending the family planning clinic, Siriraj Hospital. J Med Assoc Thai 87: 1419-1424.

25. Ashraf-Ganjoei $\mathrm{T}$ (2005) Risk factors for bacterial vaginosis in women attending a hospital in Kerman, Islamic Republic of Iran. East Mediterr Health J 11: 410415 .

26. Tibaldi C, Cappello N, Latino MA, Masuelli G, Marini S, et al. (2009) Vaginal and endocervical microorganisms in symptomatic and asymptomatic nonpregnant females: risk factors and rates of occurrence. Clin Microbiol Infect 15: 670-679.

27. Rifkin SB, Smith MR, Brotman RM, Gindi RM, Erbelding EJ (2009) Hormonal contraception and risk of bacterial vaginosis diagnosis in an observational study of women attending STD clinics in Baltimore, MD. Contraception 80: 63-67.

28. Ness RB, Hillier SL, Richter HE, Soper DE, Stamm C, et al. (2002) Douching in relation to bacterial vaginosis, lactobacilli, and facultative bacteria in the vagina. Obstet Gynecol 100: 765.

29. Ness RB, Hillier S, Richter HE, Soper DE, Stamm C, et al. (2003) Can known risk factors explain racial differences in the occurrence of bacterial vaginosis? J Natl Med Assoc 95: 201-212.

30. Koumans EH, Sternberg M, Bruce C, McQuillan G, Kendrick J, et al. (2007) The prevalence of bacterial vaginosis in the United States, 2001-2004; associations with symptoms, sexual behaviors, and reproductive health. Sex Transm Dis 34: 864-869.

31. Hensel KJ, Randis TM, Gelber SE, Ratner AJ (2011) Pregnancy-specific association of vitamin $\mathrm{D}$ deficiency and bacterial vaginosis. Am J Obstet Gynecol 204: 41.e41-49.

32. Nansel TR, Riggs MA, Yu K-F, Andrews WW, Schwebke JR, et al. (2006) The association of psychosocial stress and bacterial vaginosis in a longitudinal cohort. Am J Obstet Gynecol 194: 381-386.

33. Klebanoff MA, Nansel TR, Brotman RM, Zhang J, Yu KF, et al. (2010) Personal hygienic behaviors and bacterial vaginosis. Sex Transm Dis 37: 94-99.

34. Klebanoff MA, Andrews WW, Zhang J, Brotman RM, Nansel TR, et al. (2010) Race of male sex partners and occurrence of bacterial vaginosis. Sex Transm Dis 37: $184-190$

35. Amaral R, Giraldo PC, Goncalves AK, Junior J-E, Santos-Pereira S, et al. (2007) Evaluation of hygienic douching on the vaginal microflora of female sex workers. Int J STD AIDS 18: 770-773.

36. Hassan WM, Lavreys L, Chohan V, Richardson BA, Mandaliya K, et al. (2007) Associations between intravaginal practices and bacterial vaginosis in Kenyan female sex workers without symptoms of vaginal infections. Sex Transm Dis 34: 384-388.

37. McClelland RS, Richardson BA, Graham SM, Masese LN, Gitau R, et al. (2008) A prospective study of risk factors for bacterial vaginosis in HIV-1seronegative African women. Sex Transm Dis 35: 617-623.

38. Cohen CR, Duerr A, Pruithithada N, Rugpao S, Hillier S, et al. (1995) Bacterial vaginosis and HIV seroprevalence among female commercial sex workers in Chiang Mai, Thailand. AIDS 9: 1093-1097.

39. Yotebieng M, Turner AN, Hoke TH, Van Damme K, Rasolofomanana JR, et al. (2009) Effect of consistent condom use on 6-month prevalence of bacterial vaginosis varies by baseline BV status. Trop Med Int Health 14: 480-486.

40. Fonck K, Kaul R, Keli F, Bwayo JJ, Ngugi EN, et al. (2001) Sexually transmitted infections and vaginal douching in a population of female sex workers in Nairobi, Kenya. Sex Transm Infect 77: 271-275.
41. Perla ME, Ghee AE, Sanchez S, McClelland RS, Fitzpatrick AL, et al. (2012) Genital tract infections, bacterial vaginosis, HIV, and reproductive health issues among Lima-based clandestine female sex workers. Infect Dis Obstet Gynecol 2012: 739624

42. Baisley K, Changalucha J, Weiss HA, Mugeye K, Everett D, et al. (2009) Bacterial vaginosis in female facility workers in north-western Tanzania: prevalence and risk factors. Sex Transm Infect 85: 370-375.

43. Plitt SS, Garfein RS, Gaydos CA, Strathdee SA, Sherman SG, et al. (2005) Prevalence and correlates of chlamydia trachomatis, neisseria gonorrhoeae, trichomonas vaginalis infections, and bacterial vaginosis among a cohort of young injection drug users in Baltimore, Maryland. Sex Transm Dis 32: 446453 .

44. Schwebke JR, Desmond RA, Oh MK (2004) Predictors of bacterial vaginosis in adolescent women who douche. Sex Transm Dis 31: 433-436.

45. Barbone F, Austin H, Louv WC, Alexander WJ (1990) A follow-up study of methods of contraception, sexual activity, and rates of trichomoniasis, candidiasis, and bacterial vaginosis. Am J Obstet Gynecol 163: 510-514.

46. Zenilman JM, Fresia A, Berger B, McCormack WM (1999) Bacterial vaginosis is not associated with circumcision status of the current male partner. Sex Transm Infect 75: 347-348.

47. Schwebke JR, Desmond R (2005) Risk factors for bacterial vaginosis in women at high risk for sexually transmitted diseases. Sex Transm Dis 32: 654-658.

48. Harville EW, Hatch MC, Zhang J (2005) Perceived life stress and bacterial vaginosis. J Womens Health 14: 627-633.

49. Pettifor A, Delany S, Kleinschmidt I, Miller WC, Atashili J, et al. (2009) Use of injectable progestin contraception and risk of STI among South African women. Contraception 80: 555-560.

50. Bukusi E, Thomas KK, Nguti R, Cohen CR, Weiss N, et al. (2011) Topical penile microbicide use by men to prevent recurrent bacterial vaginosis in sex partners: a randomized clinical trial. Sex Transm Dis 38: 483-489.

51. Kleinschmidt I, Rees H, Delany S, Smith D, Dinat N, et al. (2007) Injectable progestin contraceptive use and risk of HIV infection in a South African family planning cohort. Contraception 75: 461-467.

52. Cherpes TL, Hillier SL, Meyn LA, Busch JL, Krohn MA (2008) A delicate balance: risk factors for acquisition of bacterial vaginosis include sexual activity, absence of hydrogen peroxide-producing lactobacilli, black race, and positive herpes simplex virus type 2 serology. Sex Transm Dis 35: 78-83.

53. Rugpao S, Sriplienchan S, Rungruengthanakit K, Lamlertkittikul S, Pinjareon $\mathrm{S}$, et al. (2008) Risk factors for bacterial vaginosis incidence in young adult Thai women. Sex Transm Dis 35: 643-648.

54. Gallo MF, Macaluso M, Warner L, Fleenor ME, Hook EW, . (2012) Bacterial vaginosis, gonorrhea, and chlamydial infection among women attending a sexually transmitted disease clinic: a longitudinal analysis of possible causal links. Ann Epidemiol 22: 213-220.

55. Fethers KA, Fairley CK, Morton A, Hocking JS, Hopkins C, et al. (2009) Early sexual experiences and risk factors for bacterial vaginosis. J Infect Dis 200: 1662 1670 .

56. Brotman RM, Melendez JH, Ghanem KG (2011) A case control study of anovaginal distance and bacterial vaginosis. Int J STD AIDS 22: 231-233.

57. Joesoef MR, Karundeng A, Runtupalit C, Moran JS, Lewis JS, et al. (2001) High rate of bacterial vaginosis among women with intrauterine devices in Manado, Indonesia. Contraception 64: 169-172.

58. Hart G (1993) Factors associated with trichomoniasis, candidiasis and bacterial vaginosis. Int J STD AIDS 4: 21-25.

59. Holzman C, Leventhal JM, Qiu H, Jones NM, Wang J (2001) Factors linked to bacterial vaginosis in nonpregnant women. Am J Public Health 91: 1664-1670.

60. Peipert JF, Lapane KL, Allsworth JE, Redding CA, Blume JD, et al. (2008) Bacterial vaginosis, race, and sexually transmitted infections: does race modify the association? Sex Transm Dis 35: 363-367.

61. Heffron R, Donnell D, Rees H, Celum C, Mugo N, et al. (2012) Use of hormonal contraceptives and risk of HIV-1 transmission: a prospective cohort study. Lancet Infect Dis 12: 19-26.

62. O'Hanlon DE, Lanier BR, Moench TR, Cone RA (2010) Cervicovaginal fluid and semen block the microbicidal activity of hydrogen peroxide produced by vaginal lactobacilli. BMC Infect Dis 10: 120.

63. O'Hanlon DE, Moench TR, Cone RA (2011) In vaginal fluid, bacteria associated with bacterial vaginosis can be suppressed with lactic acid but not hydrogen peroxide. BMC Infect Dis 11: 200.

64. Boskey ER, Cone RA, Whaley KJ, Moench TR (2001) Origins of vaginal acidity: high $\mathrm{D} / \mathrm{L}$ lactate ratio is consistent with bacteria being the primary source. Hum Reprod 16: 1809-1813.

65. Bai G, Gajer P, Nandy M, Ma B, Yang H, et al. (2012) Comparison of storage conditions for human vaginal microbiome studies. PLoS One 7: e36934

66. Mossop H, Linhares IM, Bongiovanni AM, Ledger WJ, Witkin SS (2011) Influence of lactic acid on endogenous and viral RNA-induced immune mediator production by vaginal epithelial cells. Obstet Gynecol 118: 840-846.

67. Hel Z, Stringer E, Mestecky J (2010) Sex steroid hormones, hormonal contraception, and the immunobiology of human immunodeficiency virus-1 infection. Endocr Rev 31: 79-97.

68. Wira CR, Fahey JV, Ghosh M, Patel MV, Hickey DK, et al. (2010) Sex hormone regulation of innate immunity in the female reproductive tract: the role of epithelial cells in balancing reproductive potential with protection against sexually transmitted pathogens. Am J Reprod Immunol 63: 544-565. 
69. Straub RH (2007) The complex role of estrogens in inflammation. Endocr Rev 28: $521-574$.

70. King AE, Critchley HO, Kelly RW (2003) Innate immune defences in the human endometrium. Reprod Biol Endocrinol 1: 116.

71. Schwebke JR, Morgan SC, Weiss HL (1997) The use of sequential self-obtained vaginal smears for detecting changes in the vaginal flora. Sex Transm Dis 24: 236-239.

72. Morison L, Ekpo G, West B, Demba E, Mayaud P, et al. (2005) Bacterial vaginosis in relation to menstrual cycle, menstrual protection method, and sexual intercourse in rural Gambian women. Sex Transm Infect 81: 242-247.

73. Jarosik GP, Land CB, Duhon P, Chandler R, Jr., Mercer T (1998) Acquisition of iron by Gardnerella vaginalis. Infect Immun 66: 5041-5047.

74. Srinivasan S, Liu C, Mitchell CM, Fiedler TL, Thomas KK, et al. (2010) Temporal variability of human vaginal bacteria and relationship with bacterial vaginosis. PLoS One 5: e10197.

75. Amsel R, Totten PA, Spiegel CA, Chen KC, Eschenbach D, et al. (1983) Nonspecific vaginitis. Diagnostic criteria and microbial and epidemiologic associations. Am J Med 74: 14-22.

76. Fethers KA, Fairley CK, Hocking JS, Gurrin LC, Bradshaw CS (2008) Sexual risk factors and bacterial vaginosis: a systematic review and meta-analysis. Clin Infect Dis 47: 1426-1435.

77. Lefevre JC, Averous S, Bauriaud R, Blanc C, Bertrand MA, et al. (1988) Lower genital tract infections in women: comparison of clinical and epidemiologic findings with microbiology. Sex Transm Dis 15: 110-113.

78. Moi H (1990) Prevalence of bacterial vaginosis and its association with genital infections, inflammation, and contraceptive methods in women attending sexually transmitted disease and primary health clinics. Int J STD AIDS 1: 86-94.

79. Hillier SL, Critchlow CW, Stevens CE, Roberts MC, Wolner-Hanssen P, et al. (1991) Microbiological, epidemiological and clinical correlates of vaginal colonisation by Mobiluncus species. Genitourin Med 67: 26-31.
80. Guerreiro D, Gigante MA, Teles LC (1998) Sexually transmitted diseases and reproductive tract infections among contraceptive users. Int J Gynaecol Obstet 63 Suppl 1: S167-173.

81. Dan M, Kaneti N, Levin D, Poch F, Samra Z (2003) Vaginitis in a gynecologic practice in Israel: causes and risk factors. Isr Med Assoc J 5: 629-632.

82. Grio R, Latino MA, Leotta E, Smirne C, Lanza A, et al. (2004) Sexually transmitted diseases and pelvic inflammatory disease. Minerva Ginecol 56: 141147.

83. Smart S, Singal A, Mindel A (2004) Social and sexual risk factors for bacterial vaginosis. Sex Transm Infect 80: 58-62.

84. Cauci S, Di Santolo M, Casabellata G, Ryckman K, Williams SM, et al. (2007) Association of interleukin-1beta and interleukin-1 receptor antagonist polymorphisms with bacterial vaginosis in non-pregnant Italian women. Mol Hum Reprod 13: 243-250.

85. Evans AL, Scally AJ, Wellard SJ, Wilson JD (2007) Prevalence of bacterial vaginosis in lesbians and heterosexual women in a community setting. Sex Transm Infect 83: 470-475.

86. Mares D, Simoes JA, Novak RM, Spear GT (2008) TLR2-mediated cell stimulation in bacterial vaginosis. J Reprod Immunol 77: 91-99.

87. Kampan NC, Suffian SS, Ithnin NS, Muhammad M, Zakaria SZS, et al. (2011) Evaluation of $\mathrm{BV}(\mathrm{R})$ Blue Test Kit for the diagnosis of bacterial vaginosis. Sex Reprod Healthc 2: 1-5.

88. Mascarenhas RE, Machado MS, Costa e Silva BF, Pimentel RF, Ferreira TT, et al. (2012) Prevalence and risk factors for bacterial vaginosis and other vulvovaginitis in a population of sexually active adolescents from Salvador, Bahia, Brazil. Infect Dis Obstet Gynecol 2012: 378640.

89. Artz L, Macaluso M, Brill I, Kelaghan J, Austin H, et al. (2000) Effectiveness of an intervention promoting the female condom to patients at sexually transmitted disease clinics. Am J Public Health 90: 237-244. 